Factors affecting the adjudication of historic child sexual abuse cases involving continuous memories

\title{
Charmagne Crescini
}

\author{
Thesis submitted to \\ the Faculty of Graduate Studies and Research \\ in partial fulfillment of the requirements \\ for the degree of Master of Arts \\ Department of Psychology \\ Carleton University \\ Ottawa, Ontario
}

Copyright (C) 2007, Charmagne Crescini 


$\begin{array}{ll}\begin{array}{l}\text { Library and } \\ \text { Archives Canada }\end{array} & \begin{array}{l}\text { Bibliothèque et } \\ \text { Archives Canada }\end{array} \\ \begin{array}{l}\text { Published Heritage } \\ \text { Branch }\end{array} & \begin{array}{l}\text { Direction du } \\ \text { Patrimoine de l'édition }\end{array} \\ \begin{array}{l}\text { 395 Wellington Street } \\ \text { Ottawa ON K1A ON4 }\end{array} & \begin{array}{l}\text { 395, rue Wellington } \\ \text { Ottawa ON K1A ON4 } \\ \text { Canada }\end{array}\end{array}$

Your file Votre référence ISBN: 978-0-494-33740-0 Our file Notre référence ISBN: 978-0-494-33740-0

NOTICE:

The author has granted a nonexclusive license allowing Library and Archives Canada to reproduce, publish, archive, preserve, conserve, communicate to the public by telecommunication or on the Internet, loan, distribute and sell theses worldwide, for commercial or noncommercial purposes, in microform, paper, electronic and/or any other formats.

The author retains copyright ownership and moral rights in this thesis. Neither the thesis nor substantial extracts from it may be printed or otherwise reproduced without the author's permission.
AVIS:

L'auteur a accordé une licence non exclusive permettant à la Bibliothèque et Archives Canada de reproduire, publier, archiver, sauvegarder, conserver, transmettre au public par télécommunication ou par l'Internet, prêter, distribuer et vendre des thèses partout dans le monde, à des fins commerciales ou autres, sur support microforme, papier, électronique et/ou autres formats.

L'auteur conserve la propriété du droit d'auteur et des droits moraux qui protège cette thèse. $\mathrm{Ni}$ la thèse ni des extraits substantiels de celle-ci ne doivent être imprimés ou autrement reproduits sans son autorisation.
In compliance with the Canadian

Privacy Act some supporting forms may have been removed from this thesis.

While these forms may be included in the document page count, their removal does not represent any loss of content from the thesis.
Conformément à la loi canadienne sur la protection de la vie privée, quelques formulaires secondaires ont été enlevés de cette thèse.

Bien que ces formulaires aient inclus dans la pagination, il n'y aura aucun contenu manquant.

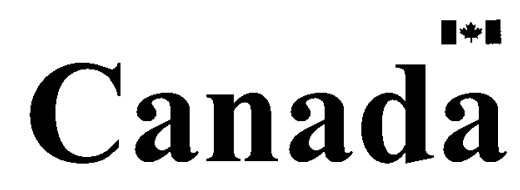




\begin{abstract}
Mock jurors $(N=295)$ read a simulated trial transcript of a historic child sexual abuse case that varied the length of delay between the alleged abuse and time of reporting ( 2 vs. 15 vs. 30 years), the complainant-defendant relationship (uncle vs. soccer coach), and abuse frequency (1 vs. 12 times). The effects of these factors on jurors' decisions were investigated. The shortest delay led to higher guilt ratings and lengthier sentence terms compared to longer delays. Mock jurors also assigned higher guilt ratings when the abuse was perpetrated 12 times rather than once, but only in the soccer coach condition. Mock jurors were more confident in their verdict decisions when the defendant was the uncle, and when the abuse occurred 12 times. In accordance with existing jury decisionmaking theories, exploratory analyses of how mock jurors' beliefs affected verdict decisions were included. Limitations, suggestions for future research, and implications are discussed.
\end{abstract}




\section{Acknowledgements}

First and foremost, I would like to extend my deepest gratitude to my supervisor, Dr. Joanna Pozzulo, for her relentless support, guidance, and enthusiasm that enabled me to successfully complete this thesis. I am extremely grateful for your time, all the opportunities you have provided me, and all the laughs that we have shared over the past two years. Thank you for everything.

To my family, especially my parents, thank you for your endless encouragement, understanding, and love. Without your assistance, I would not have been able to further my education and achieve my goals.

Many thanks to all my friends who have been so patient with me for the past two years. I would especially like to thank April, Lindsay, Angela, Denise, and Bernice. Thank you all for keeping me sane.

My appreciation also goes out to my committee members for their time and invaluable feedback, and to Etelle, for all her assistance and encouragement. Thanks to my lab mates, Monica, Julie L., Julie D., and Emily, for all the help and support.

Last, but far from least, my deepest appreciation and love goes to Jack who has been more patient and understanding than anyone throughout my degree. Thanks for being incredibly selfless, for always believing in me, and for supporting me no matter what I have chosen to do. I am so grateful to have you in my life and I cannot wait to start our life together. 
Abstract .ii

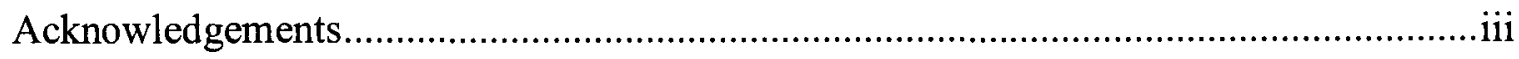

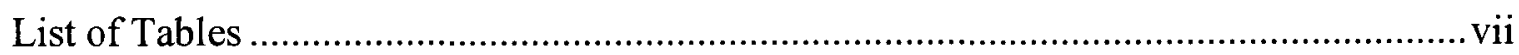

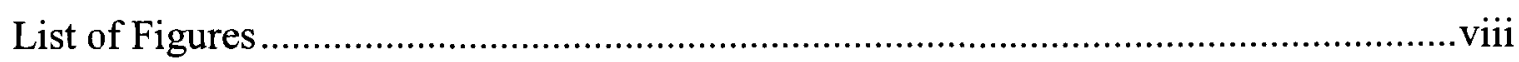

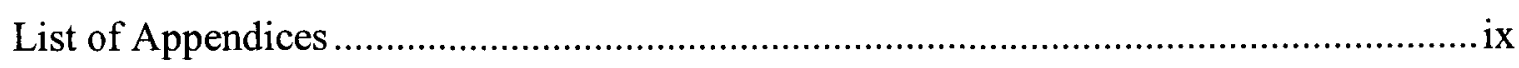

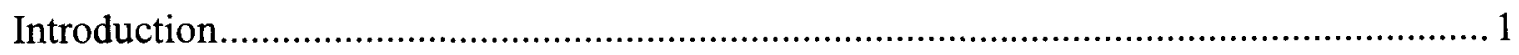

Definition of Child Sexual Abuse ............................................................... 1

Definition of Historic Child Sexual Abuse .......................................................... 2

Prevalence and Incidence Rates of Child Sexual Abuse........................................ 4

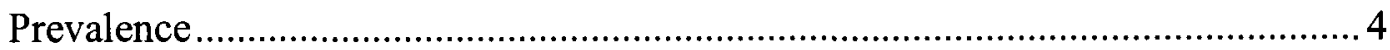

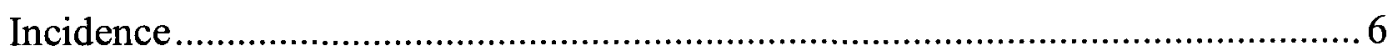

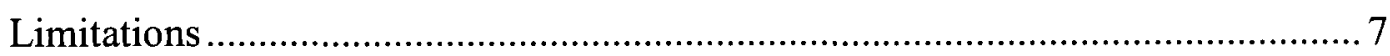

Child Sexual Abuse Research .....................................................................

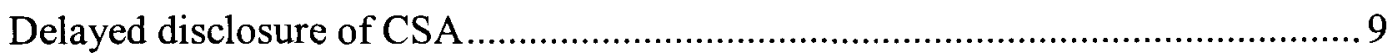

The repressed memory vs. false memory controversy .................................. 14

Jury Simulation Research on HCSA Factors ................................................ 21

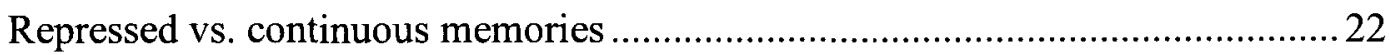

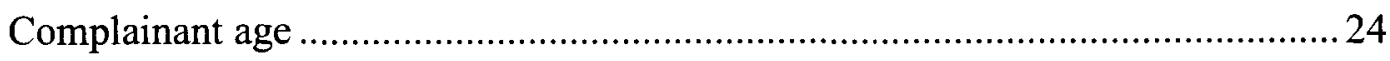

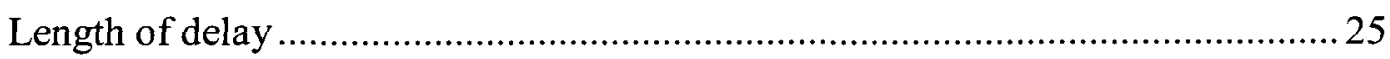

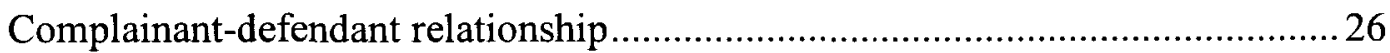

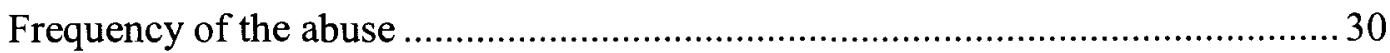

iv 


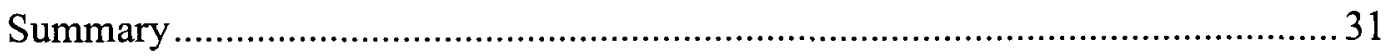

The Story Model of Jury Decision-making ................................................................. 32

The Story Model and HCSA cases ....................................................................... 34

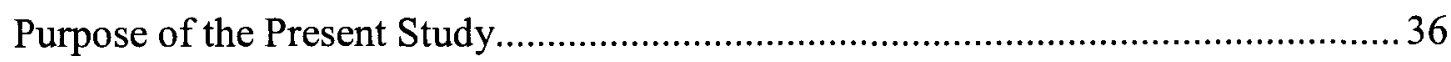

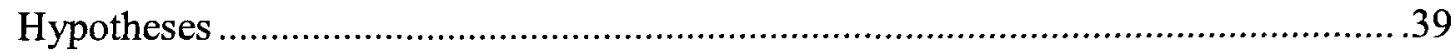

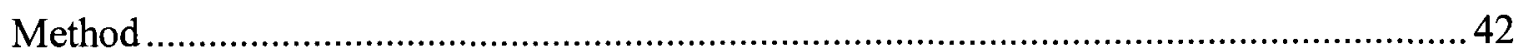

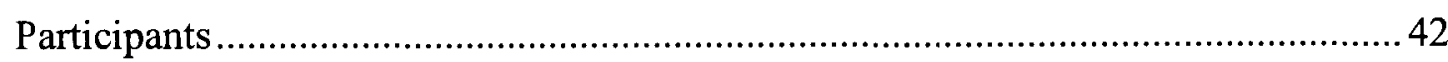

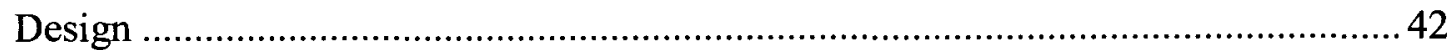

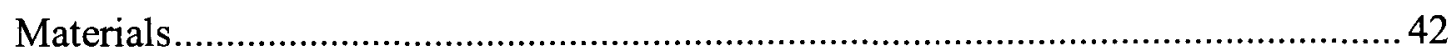

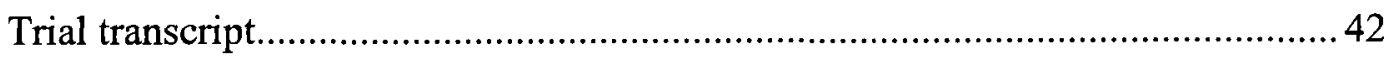

Credibility ratings form ................................................................................... 43

Verdict and verdict confidence form .................................................................. 44

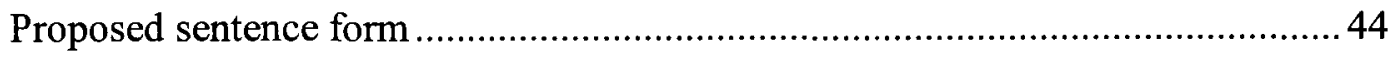

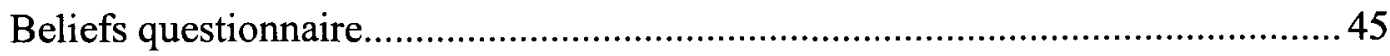

Manipulation check form ............................................................................. 45

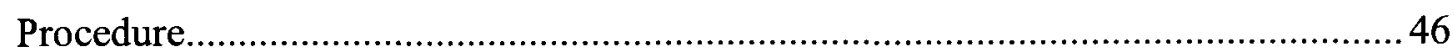

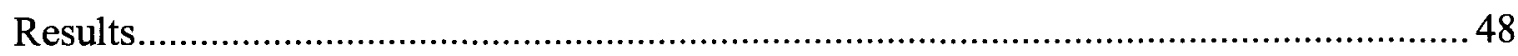

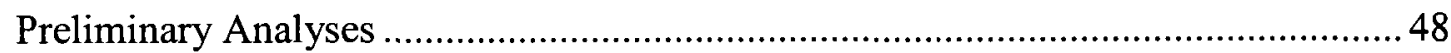

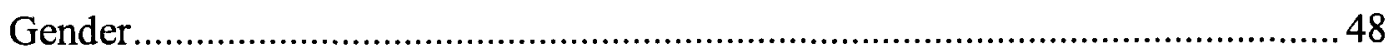

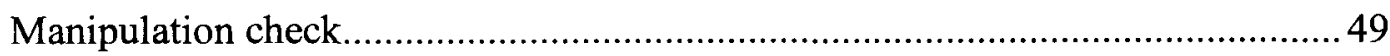

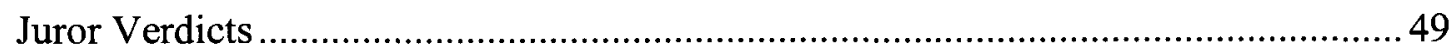

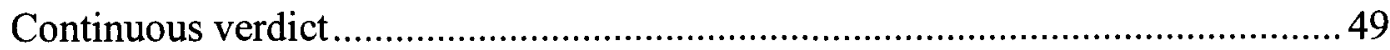




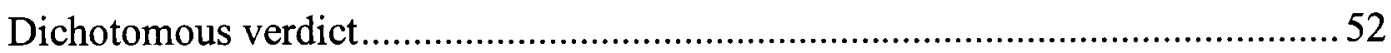

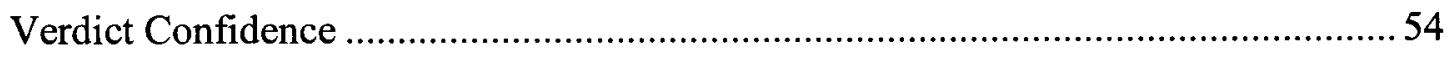

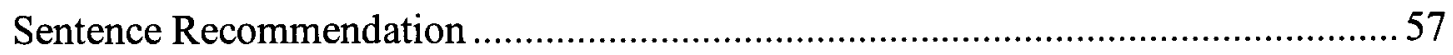

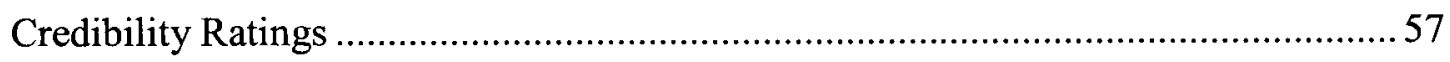

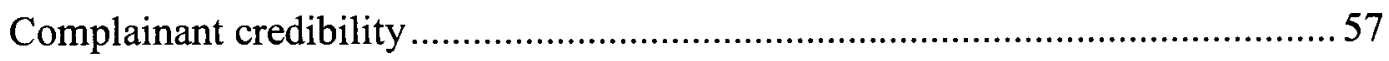

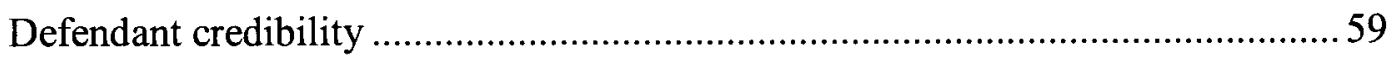

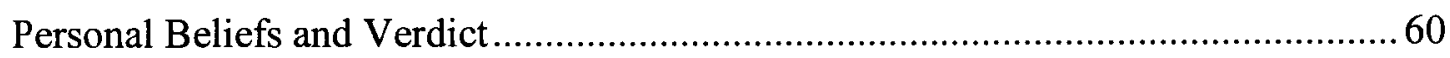

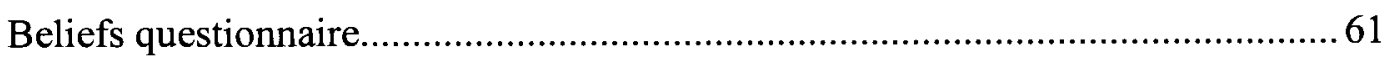

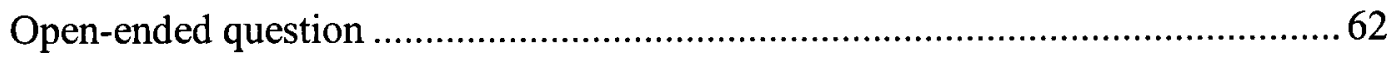

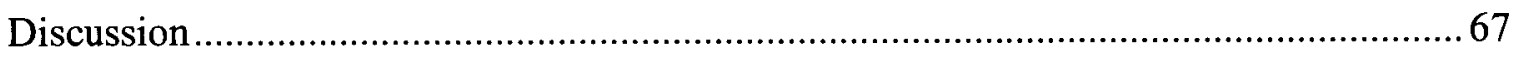

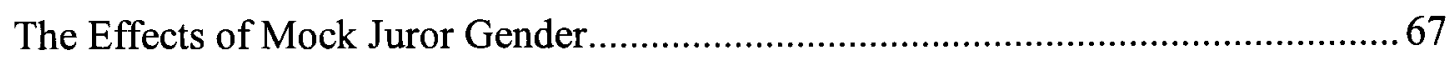

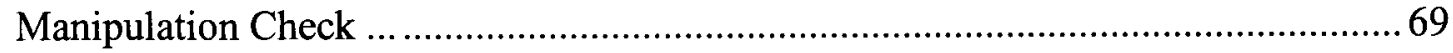

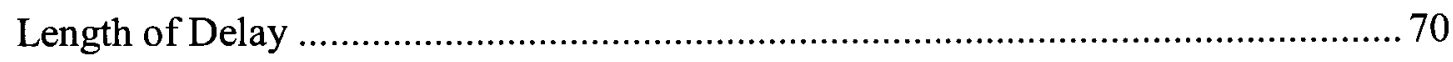

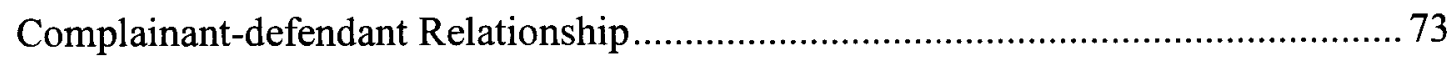

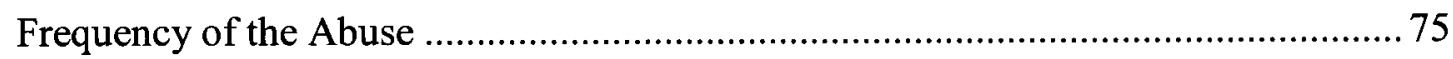

Personal Beliefs and Verdict Reasons............................................................. 76

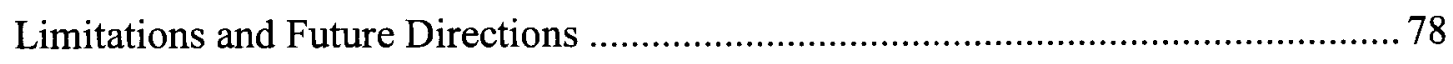

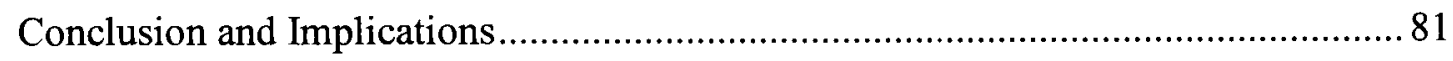

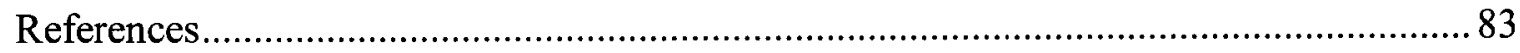

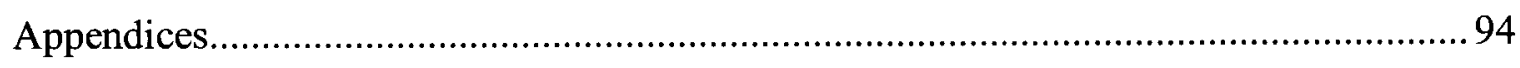

$\mathrm{vi}$ 


\section{List of Tables}

Table 1. Mean guilt ratings as a function of length of delay, complainant-defendant relationship, and frequency of the abuse

Table 2. Logistic regression predicting verdict from length of delay, complainantdefendant relationship, abuse frequency, and mock juror gender

Table 3. Logistic regression predicting sentence term recommendation from length of delay, complainant-defendant relationship, and abuse frequency 58

Table 4. Correlations between the three questions assessing the overall credibility of the complainant .59

Table 5. Correlations between the three questions assessing the overall credibility of the defendant.

Table 6. Logistic regression predicting verdict from participants' agreement with statements from the Beliefs Questionnaire

Table 7. Frequency of most cited responses to the open-ended question assessing participants' reasons for verdict choice 65 


\section{List of Figures}

Figure 1. Interaction plot showing mean guilt ratings for the defendant as a function of complainant-defendant relationship and frequency of the abuse. 53

Figure 2. Mock jurors' mean verdict confidence ratings as a function of complainantdefendant relationship. 56

Figure 3. Mock jurors' mean verdict confidence ratings as a function of frequency of the abuse. 56

viii 


\section{List of Appendices}

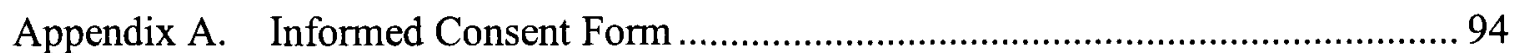

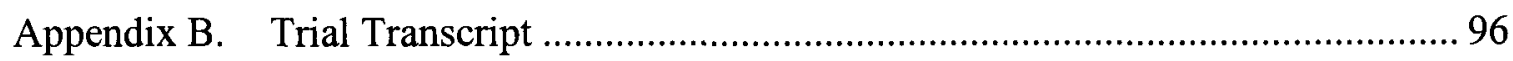

Appendix C. Credibility Ratings Form …………………...................................... 103

Appendix D. Verdict and Verdict Confidence Form................................................... 104

Appendix E. Proposed Sentence Form .................................................................. 105

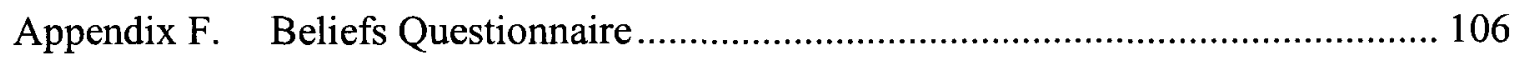

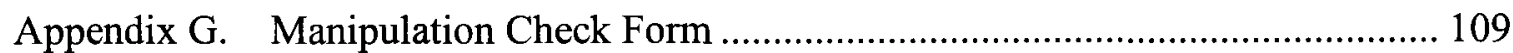

Appendix H. Written Debriefing Form ................................................................ 110

Appendix I. Verbal Debriefing Form ………………………………………….... 112

Appendix J. Reasons for Jurors' Verdict............................................................... 113 
Factors affecting the adjudication of historic child sexual abuse cases involving continuous memories

Recent archival studies based on actual Canadian cases of historic child sexual abuse (hereinafter, HCSA) have indicated that only a small percentage of these cases involve issues of memory repression and over $90 \%$ of cases involve continuous memories of abuse. Despite this, the vast majority of jury simulation studies conducted, for the purpose of informing the legal community on how HCSA cases are perceived by potential jurors, involve repressed memories. As such, there is a clear gap between the research interests of the scientific community and actual HCSA issues encountered by the legal system. Further, there is a significant lack of research on the influence of several factors on mock juror perceptions of HCSA cases, even though these factors have been consistently found to have significant effects on the timely disclosure of abuse and are arguably related to greater HCSA trauma. The present study aimed to address this gap and lack of research by investigating factors that influence the adjudication of HCSA cases involving continuous memories of abuse.

\section{Definition of Child Sexual Abuse}

Numerous definitions of child sexual abuse (hereinafter, CSA) are available in the extant literature. The concept of CSA is flexible and often, functionally defined. Some researchers limit their definition to include only those experiences that are coerced or unwanted in nature (e.g., DeGroot, Kennedy, Rodin, \& McVey, 1992; Young, 1990). Prevalence studies, on the other hand, include everything from non-contact behaviors 
(e.g., exhibitionism) to actual sexual intercourse in the definition of CSA (Badgley et al., 1984; Finkelhor, Hotaling, Lewis, \& Smith, 1990), while legal definitions cover an even wider range of acts, from involving a child in prostitution or pornography, to direct abusive behaviors such as rape, incest, or sodomy (Department of Justice Canada, 2006). The lack of consensus in defining CSA as a fixed set of behaviors creates a major challenge, not only in terms of realizing the true scope of the problem, but also when comparing results across research studies.

Finkelhor (1994) suggests that in general, scientific research and legal definitions of CSA often require two simple elements: (1) sexual activities involving a child and (2) an "abusive" condition (p. 32). The first element refers to activities with children that are intended for sexual stimulation, categorized as contact or non-contact sexual abuse. The second element, abusive condition, exists when the perpetrator has a large age or maturational advantage over the child, when s/he is in a position of trust or authority, or when the activities are carried out using coercion or trickery. These conditions highlight the unequal power relationship between the child and the perpetrator and thus violate the societal notion of consensuality (Finkelhor, 1994). For the purposes of the present study, child sexual abuse was defined in these terms.

\section{Definition of Historic Child Sexual Abuse}

Historic child sexual abuse differs from CSA only in a temporal manner.

Connolly and Read (2003) defined HCSA as child sexual abuse that is alleged to have occurred in the distant past (therefore, historic) and thus involves delayed allegations. At 
present, a precise legal definition of "historic" does not exist aside from vague references to "several years or decades" (Connolly \& Read, 2006, p. 413). Given that HCSA concerns "stale" legal claims, Connolly and Read (2006) relied on the statute of limitations as a guide to attempt a definition of "historic" in their analysis of 2,064 Canadian cases of HCSA tried between 1986 and 2002. They found that in eight of the nine common-law provinces (i.e., with the exception of Nova Scotia) and in all three territories in Canada, the limitations period for personal injury actions is two years (i.e., legal proceedings can commence only within a two-year period from the day the claim is discovered; CANLII, 2005, as cited in Connolly \& Read, 2006). Similarly, in 21 jurisdictions in the United States, the statute of limitations on civil cases involving personal injury is also two years long (Nolo, 2005, as cited in Connolly \& Read, 2006). Further, in both Canada and the United States, if the offence under consideration is a recurring offence, the limitations period begins when the offence under investigation ends.

Connolly and Read (2006) thus argue that a CSA case should be deemed "historic" if two or more years had elapsed from the end of the alleged offence to the trial date. However, a problem with this definition is that the 2-year delay might simply be due to common time delays to trial and as such, might represent matters of delayed prosecutions and not necessarily delayed allegations as stated in their earlier definition. For the purposes of their analysis of actual HCSA cases however, Connolly and Read (2006) found that it was unusual for trial judges to report either the date of the official complaint or the charge date and hence, trial date was the most reliable data that could be 
obtained. For the present study, given that a mock trial scenario was used and thus avoided such methodological concerns associated with archival research, a CSA case was considered historic if there was a delay of two or more years between the end of the alleged offence and the official complaint (i.e., time of reporting); consequently, the issue of delayed allegations instead of delayed prosecutions is central, reflecting the original definition of HCSA proposed by Connolly and Read (2003).

\section{Prevalence and Incidence Rates of Child Sexual Abuse}

Prevalence. When the widespread existence of CSA in North America was discovered (or re-discovered; see Olafson, Corwin, \& Summit, 1993) in the early 1980s, there was a huge interest in documenting the true prevalence rates of CSA. The true prevalence rate refers to the number of individuals in the entire population who have ever been sexually abused as a child (Leventhal, 1990). This number is unknown and is best represented by the reported prevalence rate obtained from large-scale, retrospective surveys asking adults about occurrences of sexual abuse in childhood. In the United States, the most commonly cited figures come from the Los Angeles Times Poll (LATP) survey of 1,481 adult women and 1,145 adult men that indicated that $27 \%$ of women and $16 \%$ of men have experienced both contact and non-contact CSA (Finkelhor et al., 1990). In Canada, the most cited prevalence study, the Badgley Report (1984), indicated that from a national sample of 1,006 adult women and 1,002 adult men, $18 \%$ of women and $8 \%$ of men reported contact CSA, while $30 \%$ of women and $15 \%$ of men reported noncontact CSA (Badgley et al., 1984). Although both studies are arguably dated, the LATP 
and the Badgley Report remain the most comprehensive prevalence studies conducted in the United States and Canada, respectively, that included both male and female respondents, utilized a national random sample, and included in their definitions both contact and non-contact CSA; therefore, these remain the most cited figures for these two countries.

In the latest meta-analysis of $22 \mathrm{CSA}$ prevalence studies conducted among random, non-clinical North American samples, Bolen and Scannapieco (1999) indicated that $30 \%$ to $40 \%$ of women and $13 \%$ or more men have experienced $\mathrm{CSA}^{1}$. In their review, they found that the marked variations in reported prevalence rates across studies depended largely on methodological differences. For instance, the number of screening questions (i.e., questions assessing the occurrence of CSA) was found to be the most critical predictor of the stated prevalence for both males and females, with surveys using a greater number of questions associated with higher prevalence rates (Bolen \& Scannapieco, 1999; see also, Finkelhor, 1994). Perhaps a more important and surprising finding is that the definition of CSA did not significantly contribute to the variance in prevalence rates. Bolen and Scannapieco suggested that although CSA definitions would be expected to impact prevalence rates, it is possible that definitions used might have been so confounded with other factors that its main effect could not be determined. For instance, four surveys that included non-contact abuse in their CSA definition used only a single screening question, which might have led to lower disclosure rates among respondents (Bolen \& Scannapieco, 1999).

\footnotetext{
${ }^{1}$ These estimates were computed from separate data sets given that only 11 of the 22 studies included data for male respondents while all 22 included data for female respondents.
} 
Another important finding is that across prevalence studies, there are consistently lower rates of male victims compared to female victims. Available data suggests that this might be due to males being more reluctant to disclose CSA experiences than females. For instance, in the LATP, $42 \%$ of adult males compared to $33 \%$ of adult females reported non-disclosure of CSA during childhood (Finkelhor et al., 1990). This finding is consistent with studies of child victims of sexual abuse wherein boys were found to have delayed disclosure more often compared to girls (e.g., $81 \%$ vs. $58 \%$, respectively; Sas, 1993). However, Bolen (2001) suggests the possibility that CSA may be a gendered problem given that across prevalence studies, there seems to be a preponderance of male perpetrators (e.g., $83 \%$ for male victims and $98 \%$ for female victims; Finkelhor et al., 1990) while the overwhelming majority of victims are females (e.g., approximately $70 \%$ of victims are females; Finkelhor et al., 1990; Bolen, 2001). Other studies have also indicated that female perpetrators account for less than one fourth $(21.3 \%)$ of all sexual assaults on underage males (Fergusson \& Mullen, 1999) or approximately $5 \%$ of all sexual offenses against children and youth (Grayston \& DeLuca, 1999), lending credence to Bolen's assertion.

Incidence. In contrast to prevalence studies, incidence studies estimate the number of CSA cases occurring in a specific period of time (Finkelhor, 1994). Similar to the true prevalence rate, the true incidence rate is unknown because not all cases of CSA are recognized or reported. However, the incidence of reported cases is available and widely documented. Typically, the annual incidence rate is used which refers to the number of CSA investigations per 1,000 children in a given year (Trocme et al., 2005). 
For instance, the Canadian Incidence Study of Reported Child Abuse and Neglect revealed that sexual abuse was the primary or secondary reason cited in $8 \%(17,321)$ of all child maltreatment investigations conducted in 2003, an incidence rate of 3.64 cases per 1,000 children (Trocme et al., 2005). This was a conservative estimate given that the sample included only those cases that were reported to Canadian child welfare services and did not involve unreported incidents, reported cases that were screened out prior to a full investigation, new reports on cases currently undergoing investigation, and cases that were investigated only by the police. Of those cases that were investigated by child welfare services, only $23 \%$ were substantiated, $16 \%$ remained suspected, and $61 \%$ were unsubstantiated, representing incidence rates of $0.83,0.60$, and 2.21 per 1,000 children, respectively (Trocme et al., 2005). In the United States, for the federal fiscal year ${ }^{2} 2005$, $9.3 \%$ of substantiated cases of child abuse involved sexual abuse. This represented 83,810 child victims or an incidence rate of 1.12 per 1,000 children (U.S. Department of Health and Human Services [U.S. DHHS], 2007).

Limitations. Although both prevalence and incidence studies of CSA provide an estimate of the scope of the problem of child sexual abuse, they have significant limitations. For incidence studies, the most prominent limitation is that they rely solely on reported CSA cases. Some studies are even more limited in that they only include those cases that were substantiated, and thus overlook the high proportions of unsubstantiated or suspect cases (e.g., incidence rate reported by the U.S. DHHS, 2007). Another important limitation is that a vast majority of incidence studies are based on data

\footnotetext{
${ }^{2}$ The federal fiscal year refers to the 12-month accounting period used by the U.S. federal government which begins on October 1 and ends on September 30 of the following year.
} 
gathered from child protective services (CPS), whose mandate is primarily to protect children from caregivers who abuse them. Thus, incidence rates may be biased towards incidence of intrafamilial abuse (especially those perpetrated by a family member in a caregiving role) given the disproportionately higher rates of such cases reported to and investigated by CPS compared to extrafamilial abuse which may be routed through law enforcement agencies (Bolen, 2001). Consequently, incidence studies may be underestimating the number of children at risk of being sexually abused by non-family members.

In contrast, although prevalence studies based on retrospective surveys include not only victims coming to the attention of authorities but also those whose abuse were never reported or substantiated, prevalence studies rely heavily on the valid recall of respondents about abusive incidents that often occurred many years before, and thus, may be subject to fallibility or forgetting (Bolen, 2001). The accuracy of respondents' reports seems to be an underlying assumption for prevalence studies that typically do not acknowledge the possibility that some respondents might be falsely disclosing abuse that never occurred, or conversely, might be denying victimization when real instances of CSA did occur. Martin, Anderson, Romans, Mullen, and O'Shea (1993) further suggested that some CSA victims might not disclose their abusive experiences primarily because they failed to self-label as CSA victims; consequently, true victims are also not accounted for by prevalence studies.

Notwithstanding these limitations, the high prevalence and incidence rates clearly indicate that CSA is a common occurrence in North America. This widespread 
occurrence, combined with the trauma associated with CSA could account for the unprecedented and sustained interest in CSA-related research.

\section{Child Sexual Abuse Research}

Chaffin (2006) contends that for the past three decades, CSA is the dominant child maltreatment topic among psychologists and mental health professionals alike, to the extent that child sexual abuse has almost become synonymous with child maltreatment. Such a contention is confirmed by the sheer number of indexed publications in the PsycInfo database, which indicated that research on CSA exponentially increased from the mid-1980s when only a handful of publications addressed it, to over 1,000 publications annually by the late 1990s (Chaffin, 2006). Chaffin also notes that within the broad scope of psychological research on CSA-related issues, there is a considerable interest in the forensic implications of CSA that, consequently, paved the way for some of the most controversial debates in the field of psychology during the 1980s (e.g., the suggestibility and reliability of child witnesses; Ceci \& Bruck, 1993).

Delayed disclosure of CSA. One of the most widely researched topics related to CSA is the issue of delayed disclosure. Connolly and Read (2003) observed that, "delayed reporting of CSA is the norm rather than the exception" (p. 438). For instance, in a review of 11 retrospective surveys of adults with CSA histories, London, Bruck, Ceci, and Shuman (2005) found that two-thirds of adults who experienced CSA did not disclose the abuse during childhood. Similarly, in a recent survey of college students who 
reported CSA histories, Ullman (2007) found that 55\% did not disclose until adulthood. Disclosure is a critical step since intervention and protection from further abuse relies heavily on timely disclosures. Thus, factors that may delay the disclosure process have received considerable interest within the scientific and legal community. Reasons for delayed disclosure have varied across studies but several researchers (Courtois, 1988; Haugaard \& Reppucci, 1988; Sas \& Cunningham, 1995) have identified four factors that most commonly inhibit disclosure among CSA victims: (1) shame or embarrassment, (2) fear of disbelief, (3) fear of being removed from the caretaker's home, and (4) concerns for the family (i.e., destruction of the parents' relationship or dissolution of the family).

In addition to these, in a study of the disclosure patterns of child victims of sexual abuse who were referred to the Child Witness Project in London, Ontario, Sas (1993) found that the child's relationship to the perpetrator had an effect on the timing of disclosure. Children were more likely to have delayed disclosure in intrafamilial cases (i.e., cases involving immediate or extended family members) compared to extrafamilial cases (i.e., involving someone other than a family member; $79 \%$ vs. $53 \%$, respectively; Sas, 1993). From a different perspective, Sas reported that $93 \%$ of immediate disclosures involved extrafamilial abuse. Similar results were obtained in later studies (GoodmanBrown, Edelstein, Goodman, Jones, \& Gordon, 2003; Smith et al., 2000; Ullman, 2007), whereby abuse by a family member was significantly associated with longer disclosure latencies (or in some cases, non-disclosures) compared to abuse by a non-family member. For instance, Smith et al. reported that female children raped by relatives were twice as likely to delay disclosure for more than a month compared to those raped by 
non-relatives.

Goodman-Brown et al. (2003) suggested that a child may have more difficulty accepting the abuse is wrong when the perpetrator is in a position of trust or authority, especially when the child is dependent on the perpetrator for his/her basic needs (as is typical in intrafamilial relationships). Similarly, Sauzier (1989) proposed that delayed disclosure in intrafamilial cases could be accounted for by the intense loyalty that the child victim may feel towards the perpetrator; maltreated children often feel a strong emotional bond to familial perpetrators and thus view disclosure as tantamount to breaking that bond. As a result, ambivalence about disclosing the abuse ensues and the child may delay disclosure or choose to never disclose at all (Sauzier, 1989). Hence, delayed disclosure of CSA appears to be significantly related to the relationship between the child victim and his/her perpetrator.

Another potential correlate of CSA disclosure is the frequency of CSA incidents. For instance, a national survey among CSA victims found that single-episode CSA cases were related to shorter disclosure latencies compared to multiple episodes of CSA (Smith et al., 2000). In a more recent study of child victims of extrafamilial abuse, Hershkowitz, Lanes, and Lamb (2007) also found that CSA victims who experienced multiple incidents were more likely to delay their disclosure compared to victims of singleepisode CSA ( $86 \%$ vs. $25 \%$ ). It is possible that repeat victims who delay disclosure may become even more reluctant to disclose as the abuse continues due to fears of disbelief because s/he failed to report it immediately after the first occurrence. Accordingly, this results in longer disclosure latencies, or in some cases, non-disclosures (Smith et al., 
2000).

On the other hand, the relationship between multiple incidents of CSA and delayed disclosure has not been consistently validated across research studies (e.g., Lamb \& Edgar-Smith, 1994). A further concern is that most studies have investigated CSA frequency in the context of understanding its relation to long-term emotional or traumatic effects, rather than delays in disclosure. For instance, Friedrich, Urquiza, and Beilke (1986) noted that the frequency of CSA acts, especially those committed by someone close to the child, corresponded to an increase in a variety of behavioral problems (e.g. aggression, sexualized behaviors, social withdrawal, etc.). As such, further research is necessary to fully understand how CSA frequency is related to disclosure.

Other intrinsic factors (i.e., factors inherent to the offense; Connolly \& Read, 2003) related to delayed disclosure include anticipated negative reactions of parents or parental figures (e.g., Hershkowitz et al., 2007), fear of negative consequences to others such as siblings or non-offending parents, and perceived responsibility for the abuse (e.g., Goodman-Brown et al., 2003). Additional factors considered in the extant literature, but that were inconsistently found to be related to longer disclosure delays, include victim gender (Goodman-Brown et al., 2003; Sauzier, 1989), severity of the abuse and victim age at the time of the abuse (London et al., 2005), perpetrators' use of force or threats, injuries sustained during the abusive incidents, and the presence of a weapon (Sauzier, 1989; Smith et al., 2000).

Connolly and Read (2003) have proposed that in addition to these intrinsic factors, there were also three systemic factors (i.e., related to the legal system) that have 
prevented the timely disclosure and prosecution of CSA, especially during the 1980s. The first factor concerned the complaint doctrine, which stated that if a sexual assault victim did not complain at the first opportunity after the assault, the trier of fact was to draw an adverse inference with respect to the credibility or consent of the victim. This was not abrogated until 1983, and thus, sexual offences against children were next to impossible to prosecute to conviction prior to this date (Connolly \& Read, 2003). The second systemic factor involved the judicial warning regarding the dangers of convicting based on the uncorroborated evidence of an unsworn child. Children often testified as unsworn witnesses before this practice was abolished in 1988. The third factor was a pervasive "attitudinal barrier" upheld by both the legal and scientific community at the time - that children are far less reliable witnesses than adults (Connolly \& Read, 2003, p. 439).

The combination of these intrinsic and systemic factors may account for why the majority of CSA victims delay reporting for many years. Hence, most CSA cases can be classified as HCSA cases. Further, since the legal barriers described above have long been abrogated and no statute of limitations exists for indictable offences in Canada (Criminal Code, 1985), the courts are faced with the task of adjudicating an increasing number of HCSA cases. Consequently, much research attention has been devoted to understanding factors that affect how such cases are received in courts. A limitation of the available literature however is that, with the exception of a handful of research studies, the majority of published studies deal exclusively with adjudicating HCSA cases involving repressed memories. 
The repressed memory vs. false memory controversy. Perhaps one of the most intensely debated topics surrounding HCSA that has captured the attention of the media, the general public, and scientific and legal scholars alike concerns issues of memory repression and recovery. Memory refers to both the mental processes of acquiring and retaining information for later retrieval and the mental storage system that enables these processes (Ashcraft, 1994). This definition encompasses the three types of mental activities related to memory: initial acquisition of information (i.e., learning or encoding), subsequent retention (i.e., storage), and retrieval (Melton, 1963, as cited in Ashcraft, 1994). For the purposes of the present review, the issue of memory repression is of particular interest.

A memory is considered "repressed" if a memory for an event (e.g., abusive experience) was purportedly forgotten for a substantial period of time and was then subsequently remembered or recovered; it implies absolute memory loss and does not allow for partial or vague memories to exist (Seymour, 1996). Loftus, Garry, and Feldman (1994) further suggest that in establishing repression, it is necessary to prove that a memory existed in the first place. Thus, a repressed memory would still need to be successfully encoded and stored, and repression occurs due to a complete retrieval failure until it is "recovered," a process that typically occurs during the course of therapy (e.g., Rieker \& Carmen, 1986, Schuker, 1979, and Williams, 1987, as cited in Loftus, 1993). The interest in repressed memory research peaked in the 1990s when an increasing number of adults claiming that they have recovered memories of childhood sexual abuse came forward. Whereas both scientific and legal scholars were preoccupied with 
questioning the credibility of child witnesses during the mid-1980s, their efforts shifted in the 1990 s to questioning the credibility of adult witnesses who alleged that they were abused as children. As such, the repressed memory vs. false memory controversy was born.

On one side, proponents argue that repression is just one of several psychological defenses employed by individuals in the face of traumatic situations (e.g., Davis \& Schwartz, 1987; Herman, 1992). Much like the Freudian concept of repression (Freud, 1940/1963, as cited in Brown, Goldstein, \& Bjorklund, 2000) the modern definition implies that the memory becomes inaccessible because the experience was highly traumatic or emotionally unpleasant. In justifying the inaccessibility of memories for traumatic events, some have compared CSA-related amnesia ${ }^{3}$ to the amnesia experienced by combat veterans with posttraumatic stress disorder (PTSD; Herman, 1992). However, while the absence of trauma memories (purportedly due to memory repression) seems to be the most common symptom among individuals who claim to have recovered memories of CSA, combat veterans rarely, if ever, forget that they experienced trauma (Silver, 1986, as cited in Lindsay \& Read, 1995). Combat veterans may experience intrusive memories of traumatic events, but there is no known case in which veterans believed for years that nothing traumatic has ever happened to them and then suddenly remembered combat traumas (Lindsay \& Read, 1995). Thus, Lindsay and Read argue

\footnotetext{
${ }^{3}$ In the CSA literature, amnesia and repression are often used interchangeably to refer to the inaccessibility of CSA memories. Loftus et al. (1994) speculated that some researchers might be hesitant to use the term "repression" because of substantial variations in its definition that is largely dependent on who is using it; hence, some researchers might cautiously discuss studies dealing with the issue of repression without ever using the term.
} 
that documented cases of PTSD bear little resemblance to CSA cases in which individuals claim to have repressed their memories and such a comparison does not adequately substantiate the phenomena of repressed CSA memories.

A common argument made to support the validity of repression is that failure to report memories of a traumatic experience that happened in the past signifies that the individual has successfully repressed the original memory, and only within supportive contexts (such as the therapeutic atmosphere) can these traumatic experiences be accessible to memory (Brown et al., 2000). Thus, the goal of therapy is to "recover" these memories of traumatic events and bring them into consciousness (Earleywine \& Gine, 1995, as cited in Porter, Campbell, Birt, \& Woodworth, 2003). A problem with this argument however, is that it promotes the belief that most individuals seeking psychotherapy have recoverable hidden memories of CSA and hence, the primary task of the therapist is to help these clients (who initially reported no histories of CSA) recover suspected hidden memories. This becomes even more problematic given that CSA cases usually lack corroborating evidence (i.e., other witnesses aside from the victim, physical evidence, etc.) and typically, the only evidence presented is the memory purportedly recovered during therapy. However, a few studies have indicated instances whereby repressed memories were corroborated in different ways.

One oft-cited study was conducted by Williams (1994) who interviewed 129 women whose experience of CSA was validated by hospital records. Williams reported that $38 \%$ of these women failed to report their CSA experience when interviewed 17 years later. Further, out of 23 cases that included documented evidence of genital trauma, 
approximately half $(52 \%)$ of the participants had no recollection of the abusive event. It is important to note that $67 \%$ of the total sample was 7 to 12 years of age when the abuse occurred and only $9 \%$ were aged 3 years or under. Thus, a lack in cognitive development and language acquisition, factors that are associated with childhood amnesia (i.e., general lack of memories from infancy to early childhood), cannot sufficiently account for the high rate of no recall among the adult participants (Williams, 1994). In another study, Herman and Schatzow (1987) reported that $74 \%$ of adult clients who recovered new memories of CSA during a 12-week group therapy program subsequently reported corroboration of these abusive events, albeit the nature of some of the corroboration appeared weak (i.e., clients reporting that their relatives in some ways support their beliefs). Thus, it might be possible to repress and subsequently recover traumatic memories involving CSA (however, see Loftus \& Davis, 2006 for criticisms ${ }^{4}$ of such studies).

On the other side of the repressed memory debate, opponents have argued that these so-called "recovered memories" are simply the by-product of suggestive memory work carried out during the course of psychotherapy. Loftus (1993), for instance, pointed out that the methods employed by therapists in retrieving memories of CSA (e.g.,

\footnotetext{
${ }^{4}$ A common criticism concerns the ambiguity of screening questions used to elicit participants' recall of CSA incidents. For instance, Loftus et al. (1994) pointed out that affirmative responses to questions that asked participants if there ever was a time when s/he could not remember some or all of the abuse did not necessarily serve as evidence of complete memory repression (e.g., participants could have interpreted it to mean that they experienced normal forgetting but if they were asked at the time, they would remember it and report it). Loftus and Davis (2006) also noted a host of other reasons other than repression that could cause participants to fail to report the abuse during questioning 17 years later (e.g., embarrassment or lack of rapport with the interviewer). Further, they criticized the design of Williams' (1994) study that did not directly ask participants about the target incident; had they been asked, participants might have been more willing to report the incident (Loftus \& Davis, 2006).
} 
hypnosis, guided imagery, age regression, etc.) have been consistently reported as highly influential in reorganizing memory. This raises legitimate concerns, not only about changing the content of actual memories, but also with regards to the construction of "false memories" (i.e., memories for events that never happened; Loftus, 1993). Research studies have shown that the construction of false memories is not only possible but also quite simple.

In the now famous "lost-in-the-mall" study by Loftus and Pickrell (1995), participants were given brief descriptions of four events that supposedly occurred when they were between the ages of 4 and 6 . Three of these were true events supplied by family members who acted as confederates while one was a false event that suggested to participants that when they were approximately 5 years old, they had been lost in a shopping mall for an extended period of time and were eventually rescued by an elderly person. With little corroboration from the trusted family member (e.g., mother or aunt) regarding the veracity of the event, a quarter ${ }^{5}$ of the participants became convinced that they experienced being lost as a child. Participants would even expand on the initial suggestion and "recover" memories about feeling scared, about conversations that supposedly took place between the participant and the family member when they were reunited, as well as descriptions of the person who supposedly came to their rescue. Similar results were achieved in other studies (Lindsay, Hagen, Read, Wade, \& Garry, 2004; Wade, Garry, Read, \& Lindsay, 2002), thus providing evidence that false

\footnotetext{
${ }^{5}$ For the remaining $75 \%$ who failed to accept the false memory, Loftus and Pickrell (1995) noted that the clarity ratings for the false "lost" events and the number of descriptive words used by participants to describe them tended to be lower than for the true events and thus, could explain why these participants resisted the suggestion of being lost.
} 
autobiographical memories are easily created.

Other researchers (Pezdek, Finger, \& Hodge, 1997; Pezdek \& Hodge, 1999) however, have argued that these studies involved the creation of false memories of innocuous childhood events and continued to question the ease at which false memories for emotional or traumatic childhood events can be created. Specifically, Pezdek et al. (1997) reasoned that event plausibility and schematicity information (i.e., script-relevant knowledge) might play a role in how successful false memories are implanted or incorporated with memories for real events. For instance, getting lost in a shopping mall may be considered highly plausible because it is likely that most people have experienced being lost at one point during their childhood and may also have a welldeveloped generic script for the experience of being lost. In contrast, memories for something that is unlikely or for which individuals are unfamiliar with (e.g., how an enema is performed) would not be as easily implanted (Pezdek et al., 1997). For example, Pezdek et al. found a $0 \%$ success rate at implanting a false memory of experiencing an enema and a $15 \%$ success rate at implanting false memories for getting lost in a shopping mall (Experiment 2). Thus, the perceived plausibility of an event and schematicity information may play significant roles in the successful implantation of false memories, and accordingly, challenge Loftus and colleagues' argument about the ease of implanting false memories.

The extent of the repressed memory controversy and the subsequent legal implications (e.g., innocent persons are being accused and prosecuted for CSA crimes) arising from this debate prompted the American Psychological Association (1998) to 
establish a working group to review the literature available thus far regarding the evaluation of CSA memories. Points of agreement among researchers that were part of the working group included (1) controversies surrounding adult recollections of CSA should not obscure the fact that CSA is a pervasive problem that has gone unacknowledged for a long time, (2) most CSA survivors remember all or part of what happened to them, (3) it is possible for CSA memories that have been forgotten for a period of time to be remembered, (4) it is possible to construct false memories, and (5) there are gaps in the current knowledge about the processes that lead to accurate and inaccurate recollections of CSA. However, the working group also acknowledged that they differed significantly on a wide range of other issues. Of particular interest for the present review were issues concerning (1) the constructive nature of memory and the accuracy with which events can be remembered after extended delays, (2) the mechanisms underlying delayed memories, and (3) the presumed "special status" of memories for traumatic events (APA, 1998, p. 933).

This debate, commonly referred to as the "memory wars" (Loftus \& Davis, 2006; p. 470), is far from resolved and its full extent is beyond the scope of the present study. An important point to consider however, is that the extensive discussion presented above is evidence of the immense and sustained interest that the scientific community has devoted to the repressed versus false memory debate. There is no question that such an undertaking is worthy and certainly holds practical significance in terms of how HCSA cases involving claims of repression are handled by the justice system. On the other hand, such cases represent a very small percentage of actual HCSA cases adjudicated in 
courts (Read, Connolly, \& Welsh, 2006). Nevertheless, a review of the literature to date, which is highly focused on HCSA cases involving repressed memories, is necessary to better understand how different factors affect juror decisions in HCSA cases.

\section{Jury Simulation Research on HCSA factors}

Numerous studies (Golding, Sego, \& Sanchez, 1999; Golding, Sego, Sanchez, \& Hasemann, 1995; Loftus, 1993; Loftus, Wiengardt, \& Hoffman, 1993; Tetford \& Schuller, 1996) have investigated how different CSA-related factors affect the decisions rendered by triers of fact (i.e., jurors). Typically, these studies have been completed in the context of whether the memory was repressed or not; therefore, the primary goal of these studies was to assess different factors that influenced jurors' perceptions of repressed CSA memories (Read et al., 2006).

The majority of these studies were conducted using a mock jury paradigm. Although some researchers (e.g., Diamond, 1997) have questioned the ecological validity of jury simulation research (e.g., use of undergraduate vs. community sample, absence of deliberations, written summaries vs. more realistic simulations), given that access to real jurors for research purposes is difficult and often limited in the United States, and illegal in Canada (Read et al., 2006), jury or juror simulation studies are necessary to better inform the legal community of the possible effects of any given factor on juror decisions. Further, Bornstein (1999) argued that the use of student mock jurors and the presentation of mock trials in written form are not necessarily cause for concern, given that there are only a handful of research studies that have obtained significantly different results 
between different mock juror samples and different trial media. In the following section, a review of mock juror studies that have investigated the impact of several factors on the adjudication of HCSA cases are presented.

Repressed vs. continuous memories. Results from studies assessing the reactions of mock jurors to repressed memories have been variable thus far. In the first of these studies, Loftus and colleagues (1993) presented participants with the case of a 20-yearold woman who accused her father of CSA that occurred when she was 10 years old. Half of the participants were informed that the woman had repressed her memory for the abuse for 10 years and the memory only resurfaced during the course of therapy. The other half were informed that the woman had a continuous memory (i.e., no repression was involved) of the abuse and the allegation against her father had simply been delayed for 10 years. Participants presented with the continuous memory were found to be less skeptical compared to those in the repressed memory group. Further, the alleged victim was rated as less credible and less favorable when her memory report was described as repressed compared to the continuous memory condition. Other researchers (Key, Warren, \& Ross, 1996; Tetford \& Schuller, 1996) have obtained similar results. Greater skepticism and, consequently, fewer guilty verdicts were reached in cases involving repressed memories compared to the non-repressed condition.

Other studies (e.g., Clark \& Nightingale, 1997; Golding et al., 1995; Golding, Sanchez, \& Sego, 1999; Golding, Sego et al., 1999, Experiment 2; Stewart, Whiteside, \& Golding, 2000) however, have not found significant differences in outcome decisions 
among mock jurors presented with either repressed or non-repressed $\mathrm{HCSA}^{6}$. For instance, Golding, Sanchez et al. (1999) found that although jurors' decisions in a mock civil case involving HCSA was significantly affected by the timing of reporting (i.e., delayed reporting led to lower ratings in favor of the plaintiff compared to immediate reporting), there were no significant differences ${ }^{7}$ between the repressed and nonrepressed delay conditions. Accordingly, across studies, the repressed and non-repressed conditions were typically collapsed to allow for meaningful comparisons with the immediate condition.

Further, in direct contrast to Loftus et al. (1993) and other researchers, a study conducted by Sugarman and Boney-McCoy (1997) indicated that mock jurors assigned more guilty verdicts to testimonies involving repressed memories than non-repressed memories. The authors proposed that jurors might have considered the repressed versus non-repressed distinction as a "proxy for the perceived severity of the assault" to explain this unexpected outcome (Sugarman \& Boney-McCoy, 1997, p. 122). More specifically, mock jurors might have perceived abusive incidents that resulted in memory repression

\footnotetext{
${ }^{6}$ It is important to note that, with the exception of the Clark and Nightingale study, all of these studies that consistently found no differences in juror decisions for the repressed versus non-repressed delay conditions were conducted by a single research team (i.e. Golding and his colleagues). Drawing from the eyewitness literature, results from a recent meta-analytic review on the sequential superiority effect have indicated that studies emanating from a single laboratory produced significantly different results compared to studies conducted elsewhere (for a fuller account, see McQuiston-Surrett, Malpass, \& Tredoux, 2006). McQuiston-Surrett et al. found that the difference was primarily due to procedural variations between studies conducted in the laboratory in question and the rest of the studies. In much the same way, the author of the present study speculates that it is possible that the methodologies employed by Golding et al. may differ from studies conducted by other researchers, and as a result, may account for the consistent non-significant findings when comparing juror perceptions of repressed versus non-repressed delays in reporting.

${ }^{7}$ It is noteworthy that across studies, the non-significant differences in juror decisions for the repressed versus non-repressed conditions cannot simply be attributed to small sample sizes or a lack of power given that these differences are often negligible (e.g., the proportion of jurors deciding for the plaintiff was .40 in the repressed condition vs. .38 for the non-repressed condition; Golding et al., 1995).
} 
as indicative of being more severe than abusive memories that were never repressed, and thus, rendered more guilty verdicts in the repressed condition. Thus, although mock jurors appear to be highly skeptical of repressed memories, this finding has not been consistently replicated across research studies.

Complainant age. A number of studies (Bottoms \& Goodman, 1994; Gabora, Spanos, \& Joab, 1993; Nightingale, 1993) have also investigated the effects of the complainant's age on jurors' perceptions of CSA victims with consistent results; younger CSA complainants are found to be more credible than older complainants. For instance, Nightingale (1993) found that credibility ratings and guilty verdicts decreased as the age of the complainant increased (age was varied from 6 to 14 years), whereas the amount of blame attributed to the victim increased with age. Leippe and Romanczyk (1987) suggested that the effects of complainant age on mock juror decisions could be related to the weights given to each of two dimensions jurors consider in assessing witness credibility: (1) cognitive competence (i.e., memory accuracy and overall understanding) and (2) trustworthiness. When there is no motivation to lie (e.g., cases of vehicular homicide, robbery murder, or medical malpractice), cognitive competence becomes more important and older child witnesses are often viewed as more credible witnesses compared to younger ones. In contrast, in cases where questions of honesty may arise (e.g., CSA or drug abuse cases) younger child witnesses (approximately, aged 6 and under) are often perceived as less likely to lie and greater witness credibility is assigned to them (Leippe \& Romanczyk, 1987). In CSA cases, mock jurors may be particularly more likely to assign higher credibility ratings to younger children compared to older 
children and adults because of their sexual naïveté (Bottoms \& Goodman, 1994). Specifically, because they lack sexual knowledge to begin with, allegations of CSA brought forth by younger children are often believed to be true.

Northcott, Connolly, and Price (2005) argued that while this model is useful to better understand the effects of complainant age in CSA cases that are immediately disclosed and prosecuted (and hence, the complainant is still a child when s/he takes the stand), it should be less compelling in HCSA cases since trustworthiness describes a current state and would not be helpful in assessing the credibility of an adult reporting a childhood incident. Specifically, Northcott et al. contend that there is no reason to expect that a 30 -year-old describing an event that occurred when she was 5 years old would be perceived as more credible than a 30-year-old describing an event that happened when she was 12 years old. Such an argument was also supported by a ruling handed down by the Supreme Court of Canada which stated:

In general, where an adult is testifying as to events which occurred when she was a child, her credibility should be assessed according to criteria applicable to her as an adult witness. (R. v. W.(R.), [1992], as cited in Connolly \& Read, 2003)

Thus, the impact of complainant age at the time of the abuse on witness credibility assessments appears to be important only in CSA cases reported and prosecuted in a timely manner and may not hold much significance for HCSA cases due to the long delays inherent in such cases.

Length of delay. Perhaps a more important factor to consider in HCSA cases is 
the length of delay between the time the alleged abuse ended and the time it was reported and subsequently brought to trial. The age of the child at the time of the abuse may not be an issue; instead, what may hold greater importance is the number of months, years, or even decades that have elapsed since the last abusive incident. The concern for this delay is reasonable since time delays are bound to have adverse effects on memory, and thus may affect the credibility assessment of the alleged victim's memory report and the resulting juror decisions. For instance, several studies found that an increase in the number of guilty verdicts (in mock criminal cases) or decisions for the plaintiff (in mock civil cases) and higher complainant credibility ratings were associated with the immediate reporting condition (i.e., the alleged victim testified immediately following the assault) compared to when there was any type of delay in reporting (i.e., regardless of whether the delay was due to memory repression or not; Golding et al., 1995; Golding, Sanchez et al., 1999; Golding, Sego et al., 1999; Stewart et al., 2000). All of these studies however, have examined the effects of delay within the context of investigating the effects of repressed memories on mock juror verdicts. Moreover, length of delay (i.e., number of years or decades) was also not varied in these studies; typically, the number of years is kept constant (e.g., 20-year delay for both repressed and non-repressed condition; Stewart et al., 2000) in order to isolate the effects of repressed memories on juror decisions. Further research that disentangles issues of time delays from issues of memory repression is necessary to determine more conclusively the effects of delay on the adjudication of HCSA cases.

Complainant-defendant relationship. Despite the fact that victim-perpetrator 
relationship is considered an important factor related to delayed disclosure of CSA (e.g., Sas, 1993; Ullman, 2007), only two studies thus far have varied relationship (within the same study) and investigated its effects on mock jury decisions in CSA cases. In the first study, Moorthy (1998) examined the effects of the relationship between the alleged victim and the perpetrator, as well as the judge's instructions on the liability judgments rendered by mock jurors exposed to a simulated civil trial involving repressed memories of CSA. The male defendant was either related (i.e., father) or not related (i.e., gym teacher) to the female plaintiff (i.e., alleged victim in a civil trial). The judge's instructions to the jury were also manipulated. Specifically, the judge provided either supportive statements regarding the plaintiff's testimony (i.e., the judge stated that the plaintiff is presumed to be a competent witness and that it is entirely possible that the repressed memories are real) or cautionary statements (i.e., the judge stated that when someone like the plaintiff claims that they have been sexually abused during childhood, that charge is easy to make, difficult to prove, and more difficult to disprove; Moorthy, 1998). As predicted, the plaintiff-defendant relationship had a significant effect on the perceived credibility ratings, with the plaintiff rated as more trustworthy and the defendant held more responsible when the defendant was the father rather than the gym teacher. In terms of the judge's instructions, the plaintiff was also seen as more credible when the judge provided supportive rather than cautionary statements to the jury (Moorthy, 1998).

A problem with this study however, is that the transcripts provided to the mock jurors differed not only in terms of the variables under investigation. Although Moorthy 
(1998) stated that the basic transcript was the same in all four conditions, she also described how the surroundings in which the alleged CSA took place were varied to make the transcripts more believable by accommodating the difference in relationship between the plaintiff and the defendant. For instance, in the father condition, the abuse was described as having occurred in the home while the father, unable to find work during the summer, cared for the plaintiff everyday while the plaintiff's mother was at work. In contrast, the abuse that was allegedly perpetrated by the gym teacher was described as having occurred in the school's equipment room after gym class and prior to the beginning of the next class. The difference in the amount of time that the defendant in each condition spent with the plaintiff represents markedly different opportunities to perpetrate the abuse (i.e., the father appeared to have more opportunities given that they spent entire days together compared to the gym teacher who only spent time with the plaintiff after gym class prior to her next class).

Further, previous incidents raised during the cross-examination of the defendant in an attempt to damage his reputation were also different for each condition. In the father condition, the police was called because of a domestic dispute which was quickly resolved and resulted in no charges being made; in the gym teacher condition, there were two complaints against the defendant concerning his inappropriate conduct towards two female students that did not result in any formal complaints. The latter incident implied that the defendant might have had a history of inappropriate behavior towards female students, and thus makes the current allegation more plausible, while the former provided no such insinuations. As such, the significant results obtained in terms of the plaintiff- 
defendant relationship might be questionable since factors additional to the variables being investigated could have confounded the results. Further, much like the majority of mock jury studies involving HCSA cases, this study investigated the variables described above with the intention of assessing their influence on juror perceptions of cases involving repressed memories.

In a much recent CSA study, McCoy and Gray (2007) investigated the impact of defendant gender (male vs. female) and relationship to victim (parent vs. stranger) on juror decisions. In terms of defendant gender, overall, the gender of the defendant significantly affected verdict and defendant believability ratings with more guilty verdicts and lower defendant believability ratings assigned to male defendants compared to female defendants. Although the main effect of relationship on verdict was not statistically significant, McCoy and Gray did find that the two-way interaction effect approached significance $(p=.06)$. Specifically, more guilty verdicts were rendered for a male defendant but only when he was described as the father $(53 \%)$ rather than a male stranger (27\%); further, this $27 \%$ conviction rate for the male stranger was highly similar to conviction rates for female defendants, regardless of the relationship to the victim (i.e., $24 \%$ for mothers and $27 \%$ for female strangers). Similar patterns can be observed for victim believability ratings; higher believability ratings for the victim were associated with the father condition compared to the male stranger, female stranger, and mother conditions.

McCoy and Gray (2007) provided more solid evidence than did Moorthy (1998) that juror decisions may be affected by the nature of the victim-perpetrator relationship 
with more guilty verdicts associated with cases of intrafamilial compared to extrafamilial abuse (but only when the defendant is male). However, a limitation of this study (by the authors' own admission) is that the significantly higher conviction rate in the father case could be due to the fact that a case of father-daughter incest was the best representation of the "typical" CSA case (p. 1589) and thus, may have seemed more plausible than, for instance, a case of mother-daughter incest. Thus, the common nature of father-daughter incest, instead of a real difference in how potential jurors perceive intra- versus extrafamilial child sexual abuse, may account for the significant results. Nevertheless, McCoy and Gray's study contribute to the little research available on how the nature of the victim-perpetrator relationship impacts juror decisions in CSA cases.

Frequency of the abuse. Another important factor that has received little attention in jury simulation studies of HCSA is the frequency of the alleged abuse. This is surprising considering that abuse severity (as indexed by the frequency of the assault) is not only related to delayed disclosure of CSA, but also to the negative effects on psychological adjustment, and memory for the events (Read et al., 2006). Further, in Connolly and Read's (2006) meta-analytic review of actual HCSA cases, $68 \%$ of complainants alleged repeated abuse while the related literature focuses on single occurrences of CSA (e.g., Key et al., 1996). To date, only two studies have systematically investigated the effects of abuse frequency on mock juror decisions and both of these studies involved repressed memories.

Golding, Sego et al. (1999) manipulated the frequency of abuse as either occurring once or as 30 abusive events. As discussed in previous sections, this study also 
included a manipulation of the timing of reporting (i.e., immediate vs. 20 -year delay with repression vs. 20-year delay without repression). Across all reporting conditions, 30 alleged assaults led to more decisions for the plaintiff and greater believability of the plaintiff than a single occurrence of abuse, even when the memory for the assault was repressed. The authors concluded that mock jurors appeared to hold a "more is worse, more is believable" attitude in adjudicating cases of child sexual assault (Golding, Sego, et al., 1999, p. 491). Similar results were obtained by Griffith, Libkuman, Kazen, and Shafir (1999; Experiment 3) whereby mock jurors were found to assign higher monetary damages to the plaintiff and higher ratings of perceived guilt to the defendant when the case involved repeated rather than a single occurrence of abuse. However, this finding was only significant for female mock jurors (Griffith et al., 1999). In addition to the fact that both studies were primarily conducted to assess juror decisions in CSA cases involving repressed memories, a further limitation of these studies is that they involved civil cases of CSA wherein the standard of proof depends on a "balance of probabilities" (i.e., a preponderance of evidence that the allegation is true) rather than "beyond all reasonable doubt" (the standard of proof in criminal cases, which arguably, imposes a stricter criteria). Thus, the far less stringent standard of proof afforded to jurors in civil cases may have led mock jurors to render more decisions for the plaintiff than the accused in these studies.

Summary. The studies discussed reveal that several important factors have been found to influence mock juror decisions in HCSA cases. As mentioned however, the majority of these studies were conducted to assess the effects of these factors on cases 
involving repressed memories. There is no doubt that such research is valuable; it provides us with greater understanding in terms of how actual cases involving repressed memories are being received by potential jurors. On the other hand, a recent archival analysis of actual Canadian HCSA cases revealed that, overall, reports of repressed memories were infrequent with only $6 \%$ of the total sample $(N=2064)$ involving such claims (Connolly \& Read, 2006). Thus, there may be a need to refocus research efforts from cases involving repressed memories to HCSA cases involving continuous memories of abuse since these make up the vast majority of actual cases adjudicated in Canadian courts.

\section{The Story Model of Jury Decision-making}

Prior to a discussion of the purpose of the present study, it is important to discuss research aimed at understanding the juror decision-making process. The Story Model of juror decision-making provided the theoretical background for the present study.

Pennington and Hastie $(1981,1986)$ first proposed the Story Model as an alternative to the traditional mathematical models ${ }^{8}$ of juror decision-making. They argued that the existing models at the time failed to account for several aspects of juror decisions. For example, whereas information integration models (Kaplan \& Kemmerick, 1974) propose that jurors make independent evaluations of evidence items on a single dimension of culpability in order to reach a final calculation of the probability of the

\footnotetext{
${ }^{8}$ The four predominant mathematical models of jury decision-making in the 1970 s included the information integration model, Bayesian models, the Poisson model, and the sequential weighting model (for a comprehensive review of these traditional models that is beyond the scope of the present study, see Pennington \& Hastie, 1981).
} 
defendant's guilt, Pennington and Hastie (1986) found that interdependencies of evidence items are important to jurors and that jurors' final decisions involve reasoning about multi-attribute verdict categories rather than a single dimension of culpability.

The Story Model proposes that jurors impose story structures to organize and interpret information presented at trial that not only enable them to understand the evidence presented, but also facilitate the formation of a pre-deliberation verdict (Pennington \& Hastie, 1986). The story is constructed based on two sources: (1) information that is explicitly presented during the trial and (2) jurors' personal knowledge and expectations. There are three stages to the Story Model, specifically, the story construction stage, the verdict category stage, and the story classification stage.

In the story construction stage, Pennington and Hastie (1986) propose that jurors construct one or more plausible accounts or stories of "what happened" at the time of the events testified to during trial. Jurors may use their personal experiences or their knowledge of human interactions and behaviors to form several coherent stories.

In the verdict category stage, jurors learn about the decision alternatives (i.e., different verdicts). This typically occurs at the end of the trial when the judge provides the jury with instructions on the law prior to the deliberation phase. Pennington and Hastie (1986) suggest that jurors view each verdict alternative as a category with defining features (i.e., identity, mental state, action, and circumstance) and decision rules specifying their appropriate combinations. For instance, a defendant may be found guilty of murder in the first degree if $s /$ he is the true perpetrator (identity), if $s /$ he had motive and intent to kill (mental state), if s/he had insufficient provocation for the murder 
(circumstance), and if s/he killed in accordance with the plan (action; Pennington \& Hastie, 1986).

In the story classification stage, jurors attempt to determine the best match between the story features and verdict category features (Pennington \& Hastie, 1986). The standard of proof and the presumption of innocence are taken into consideration at this stage. Pennington and Hastie suggest that final verdict decisions are essentially based on how well the story created by the juror fits with the verdict categories.

Research studies (Pennington \& Hastie, 1986, 1988) have tested the validity of the Story Model of juror decision-making. For instance, Pennington and Hastie (1986) found that jurors' final verdict decisions are related to the stories that they constructed. Further, when jurors were given think-aloud protocols during their evaluation of the evidence presented at trial, they spontaneously exhibited story features containing causal events, psychological states, actions, and consequences (Pennington \& Hastie, 1986). These findings offer some support for the validity of the Story Model.

The Story Model and HCSA cases. The Story Model provides a sound theoretical framework for how jurors may reach verdict decisions in HCSA cases. Similar to most sexual assault cases, the alleged victim's memory and verbal account of the event may be the only evidence presented in cases of HCSA. There is often a lack of corroborating evidence (e.g., witnesses, DNA, etc.) and unless the defendant pleads guilty to the allegation(s), most accounts of HCSA may be considered cases of "he said, she said." As such, there may be several "gaps" in HCSA cases that jurors fill in with their own stereotypes or expectations, personal experiences, and/or knowledge about similar events 
in order for them to construct coherent stories about what may have taken place.

For instance, in HCSA cases that do not present clear reasons for delayed disclosure, jurors may be inclined to construct their own stories about why the alleged victim chose to delay disclosure of the abuse that may affect jurors' perceptions of the alleged victim, which in turn, may affect their verdict decisions. Further, because of factors related to the passage of time (i.e., memory decay, loss of physical evidence, etc.) jurors may be more inclined to discount an alleged victim's testimony after a longer versus shorter delay in reporting.

In terms of the complainant-defendant relationship, a case of extrafamilial compared to intrafamilial sexual abuse may be perceived as more likely to have occurred given the widely held misconception of the "perceived randomness" of sexual assault (Smith, Keating, Hester, \& Mitchell, 1976, as cited in Moorthy, 1998) and societal taboos concerning intrafamilial sexual abuse (i.e., incest). Further, in a recent study that investigated lay (i.e., university students and non-student adults) perceptions of child sexual and physical abuse, Bornstein, Kaplan, and Perry (2007) found that in terms of the perceived occurrence of both types of abuse, parents were viewed as more likely than babysitters (specified as a non-family member) to commit physical abuse while babysitters were seen as more likely to commit sexual abuse. Consequently, the defendant in a case of extrafamilial sexual abuse may be perceived as more likely to be guilty than a defendant in a case of incest. Without corroborating evidence however, jurors may perceive incest as representing a greater level of betrayal of trust and violation of boundaries than abuse by someone outside the family (Moorthy, 1998). Thus, if jurors 
believe and construct an intrafamilial story of abuse, the defendant in this case may be perceived as more likely to be guilty and may be given a harsher sentence than a defendant in an extrafamilial sexual abuse case.

In terms of frequency of the abuse, multiple occurrences of abuse may be seen as more likely to have occurred and less likely to be "misunderstood" by the child. Thus, a defendant in such a case may be perceived as more likely to be guilty compared to a case involving a single occurrence of abuse.

Within the theoretical framework of the Story Model of decision-making, the following section outlines the rationale for the variable manipulations and the expected effects of these variables on the adjudication of HCSA cases involving continuous memories of abuse.

\section{Purpose of the Present Study}

The present study investigated the effects of length of delay, complainantdefendant relationship, and frequency of abuse on mock juror perceptions of HCSA cases involving continuous memories of the abuse. The length of delay that has elapsed from the time the alleged abuse ended to the time when the alleged victim reported the abuse was indexed by the age of the complainant at the time of reporting. Specifically, the complainant was described as being 10 years old when the alleged abuse ended and was either 12,25 , or 40 years old at the time of reporting. This translated to a $2-, 15-$, or $30-$ year delay. An age of 10 years was chosen for the present study to correspond with recent findings that most victims of HCSA were between 9 to 10 years old when the 
abuse began and about 12 years old when it ended (Connolly \& Read, 2006; see also, Sas, 1993). Further, the age manipulations at the time of reporting were chosen based on findings that on average, the age of the complainant at trial was 26 years old (Connolly \& Read, 2006). Thus, a complainant age of 25 years (which translates to a delay of 15 years) was chosen to represent one of the age manipulations. Twelve years of age (which translates to a two-year delay) was chosen to represent the most immediate delay that still satisfied the minimum requirement of two years to be considered an HCSA case as defined in the present study. Forty years of age (which represents a 30-year delay) was used to represent the longest delay and mimic real-life cases involving "older" female alleged victims.

It is important to note that delays from the time of reporting to the trial date, despite being highly common in real-life cases, were not considered in the present study given that it could potentially confound the results. For instance, if we consider typical time delays to trial to be 2 years long, then the 2-year delay in reporting described above might be perceived by some mock jurors as a 4-year delay if they fail to differentiate between a delay in reporting (i.e., delay between the end of the offense and when it was reported - the main characteristic of HCSA) and a delay to trial (i.e., delay between reporting and the trial date - common across all types of cases). Thus, for the sake of clarity (albeit, at the cost of ecological validity), the mock trial scenario included only descriptions of delayed reporting and implicitly assumed that the case went to trial immediately after it was reported.

The complainant-defendant relationship also was investigated in the present 
study. A male defendant was selected for the present study given that prevalence and incidence studies alike have indicated that CSA perpetrators are most often males (Badgley et al., 1984; Trocme et al., 2005). An uncle was chosen to represent the defendant in a case of intrafamilial abuse given the finding that non-parental relatives represented the largest group of perpetrators (35\%) among substantiated CSA cases reported to child welfare services in 2003 (Trocme et al., 2005). In addition, of relatives who abuse, uncles were reported as the most frequent perpetrators (e.g., out of the $29 \%$ of respondents who disclosed intrafamilial abuse, $14 \%$ were abused by uncles; Finkelhor et al., 1990). In contrast, the alleged victim's former soccer coach was chosen to represent the defendant in the case of extrafamilial abuse. A former soccer coach is classified as an "acquaintance," which according to Sas (1993) represents the majority of extrafamilial abuse cases compared to those perpetrated by a complete stranger.

Specifically, in her study, less than $9 \%(n=16)$ of the children alleged abuse by a stranger compared to $53 \%$ who alleged abuse by individuals known to them but who were not immediate or extended family members.

The third variable investigated was the frequency of abuse, which included either a single occurrence or multiple occurrences of abuse (i.e., 12 times). This manipulation was specifically meant to test Golding, Sego, and colleagues' (1999) assertion that mock jurors tend to hold a "more is worse, more is believable" attitude towards CSA cases (p. 491).

The influence of these three factors on mock juror decisions in HCSA cases involving only continuous memories was investigated in the present study. In addition, in 
accordance with the Story Model, exploratory analyses were conducted to investigate the extent to which mock jurors' preexisting beliefs and personal experiences might affect their rendered verdicts in cases of HCSA. Of particular interest was whether jurors' preexisting beliefs concerning the three factors under investigation (i.e., delay, relationship, and frequency of the abuse) would be related to their verdict decisions. There might be some evidence to suggest that such beliefs could predict mock juror verdicts, given previous findings. For instance, Bottoms (1993) found that individuals' attitudes and beliefs were predictive of their perceptions of CSA child victims and perpetrators. More importantly, the robust gender differences in juror perceptions (i.e., females were typically found to be pro-victim and males to be pro-defendant; Gabora et al., 1993) were found to be accounted for by mock jurors' attitudes rather than mock juror gender (Bottoms, 1993). As such, the present study explored how attitudes and beliefs that were specifically related to the three factors under investigation, rather than juror gender, might predict mock juror verdicts.

\section{Hypotheses}

Length of delay. Consistent with previous findings (e.g., Golding et al., 1995, Experiment 2), it was hypothesized that mock jurors would render higher ratings of guilt when there are shorter compared to longer delays in reporting (hypothesis $1[\mathrm{H} 1]$ ). It was further hypothesized that mock jurors would assign higher credibility ratings to the complainant when there are shorter compared to longer delays in reporting $(\mathrm{H} 2)$. 
Complainant-defendant relationship. Consistent with previous research (McCoy \& Gray, 2007; Moorthy, 1998), it was hypothesized that mock jurors would render higher ratings of guilt when the defendant is a family member (i.e., uncle) rather than a non-family member (i.e., soccer coach; H3). It was also hypothesized that mock jurors would give longer sentence recommendations when the defendant is the uncle rather than the soccer coach given the expectation that the incestuous nature of the intrafamilial abuse would elicit harsher punishment from mock jurors compared to abuse perpetrated by a non-family member (H4).

Frequency of the abuse. Consistent with the findings of Golding, Sego et al. (1999), it was hypothesized that mock jurors would hold a "more is worse, more is believable" attitude and thus render higher ratings of guilt when the number of assaults is 12 rather than 1 (H5). Using the same rationale, it was hypothesized that mock jurors would be more confident in their verdict when the number of assaults is 12 rather than 1 (H6) and that mock jurors would give longer sentence recommendations when the number of assaults is 12 rather than $1(\mathrm{H} 7)$.

Interaction. It was hypothesized that mock jurors would assign higher credibility ratings to the complainant and lower credibility ratings to the defendant when there are shorter compared to longer delays in reporting, when the defendant is the uncle, and when the number of assaults is 12 rather than $1(\mathrm{H} 8)$. Credibility ratings were hypothesized to be most likely to be affected by a three-way interaction given that in some previous studies (e.g., Clark \& Nightingale, 1997; Tetford \& Schuller, 1996) that 
were unable to find significant differences in mock juror verdicts, significant differences in credibility ratings were detected.

Mockjuror beliefs. Given the exploratory nature of the analyses on the effects of mock juror beliefs on verdict decisions, no specific hypotheses regarding beliefs were made. 
Method

\section{Participants}

Two hundred and ninety-five participants (189 women and 106 men) were recruited from the first year psychology research participant pool and from upper-level psychology classes at Carleton University in Eastern Ontario, Canada. Participants $(M=$ $21.86, S D=4.28$, range: $18-53$ years) were required to be at least 18 years of age to most closely approximate juror eligible individuals (Juries Act, 1990). The majority (74\%) of participants were Caucasian, reflecting the overall population of the Ottawa-Gatineau area which is $80 \%$ Caucasian (Statistics Canada, 2003). Eighty-nine percent indicated English as their primary language. First year participants received course credit in exchange for their participation while upper-level students participated voluntarily.

\section{Design}

A 3 (length of delay; 2 vs. 15 vs. 30 years) $\times 2$ (relationship to the complainant; uncle vs. soccer coach) $\times 2$ (frequency of the abuse; 1 vs. 12 ) between-subjects factorial design was used in the present study. The dependent variables included verdict, verdict confidence, credibility appraisals of the complainant and the defendant, and a proposed sentence term if the defendant was found guilty.

\section{Materials}

Trial transcript. Twelve versions of a simulated trial transcript (see Appendix B) detailing a criminal trial involving an HCSA case were created for the present study. The 
complainant was Miss Susan Johnson who was allegedly abused when she was 10 years old. She claimed that during a car ride home from soccer practice, the defendant, Mr. John Ferguson, sexually touched her. Miss Johnson was described as having a continuous memory for the abuse, but delayed reporting it for a number of years due to feelings of intense fear that she would not be believed. Although Mr. Ferguson agreed to the fact that he gave Miss Johnson numerous rides after soccer practice, he claimed that the alleged abuse never happened. The transcript included opening statements by the Crown and Defence, the examination and cross-examination of the complainant, defendant, and character witnesses, and the judge's charge to the jury.

The basic transcript was the same for all twelve conditions; however, the conditions varied in terms of the age of the complainant at the time of the trial (to indicate the length of delay), the complainant-defendant relationship, and the number of assaults allegedly perpetrated by the defendant. The complainant was described as being 12,25 , or 40 years old at the time of the trial. The defendant was described as either the uncle or the former soccer coach of the complainant. The number of assaults was either 1 or 12 times.

Credibility ratings form. Participants were presented with Likert-type statements that assessed their perceptions of the testimonies from the complainant and the defendant (see Appendix C). In particular, participants were asked to rate how convincing the testimonies of both the complainant and defendant were on a 7-point scale $(1=$ Not at All Convincing to $7=$ Extremely Convincing), the reliability of their respective memories (1 
$=$ Not at All Reliable to $7=$ Extremely Reliable $)$, and the perceived accuracy of their respective memories $(1=$ Not at All Accurate to $7=$ Extremely Accurate $)$.

Verdict and verdict confidence form. Participants were asked to render a verdict on a continuous scale from $0 \%$ (Not at all Guilty) to $100 \%$ (Definitely Guilty) in addition to rendering a dichotomous verdict choice of Guilty or Not Guilty (see Appendix D). A continuous scale allowed for greater sensitivity to detect statistical differences in verdict outcome. On the other hand, dichotomous judgments held greater ecological validity and may not be comparable to a continuous measure and as such, were also utilized in the present study. Verdicts were followed by a 7 -point confidence scale $(1=$ Not at All Confident to $7=$ Extremely Confident) that assessed how confident participants were about their verdict decisions. Participants were then presented with an open-ended question that asked them to describe how they reached their verdict. Specifically, participants were asked, "In your own words, please describe in the space below how you made your final verdict decision (i.e., what factors did you consider in reaching your verdict of guilty or not guilty)."

Proposed sentence form. Participants who found the defendant guilty were asked to choose a sentence recommendation from a range of 45 days (minimum sentence) to 10 years (maximum sentence; see Appendix E) in accordance with the Criminal Code (1985). Participants were asked to select one of the seven options presented, each corresponding to a specific range of sentence length $(1=45$ days, $2=2-11$ months, $3=$ $1-2$ years, $4=3-4$ years, $5=5-6$ years, $6=7-8$ years, $7=9-10$ years $). \quad$ Participants who 
found the defendant not guilty were asked to skip this page and continue answering the next set of questions.

Beliefs questionnaire. Participants were asked to indicate on a 7-point scale the degree to which they disagreed or agreed $(1=$ Strong Disagree to $7=$ Strongly Agree $)$ with a number of statements (see Appendix F). The questionnaire was created specifically for the present study and assessed participants' knowledge and beliefs concerning the three factors under investigation and the issue of HCSA. The majority of these statements $(1,2,3,4,6,7,9,10,12$, and 13) reflected child sexual abuse myths formulated based on the review of the extant literature. Examples of such statements include, "Individuals who delay reporting child sexual abuse are more likely to be lying or to be making up their abusive experience" and "Children are less likely to be sexually abused by a trusted adult." Two statements ( 5 and 8 ) assessed participants' opinions about the severity of penalties assigned to perpetrators of HCSA based on the perpetrator's relationship to the complainant (statement 5) or the frequency of the abuse (statement 8). Lastly, statement 11 assessed participants' knowledge regarding delayed disclosure of CSA, as this statement reflects one of the most typical reasons for the delay. Participants' beliefs ratings were used to explore whether their personal beliefs were able to accurately predict verdicts rendered on a dichotomous scale.

Manipulation check form. The manipulation check form (Appendix G) consisted of five multiple-choice questions. Three of these (questions 1, 3, and 4) directly assessed the salience of the experimental variables while the other two (questions 2 and 5) were filler questions. 
Procedure

First year participants were tested in groups of up to 10 in the laboratory. They were randomly assigned to read one of the twelve trial transcripts. Although tested in groups, participants were separated with privacy folders. Upper-level participants were tested in their respective classrooms once permission to collect data was granted by the instructors. For the classroom setting, questionnaire packages were prepared beforehand and randomly distributed to students who agreed to participate. All participants were asked to make their decisions individually and were not permitted to discuss their responses with one another. The complete random assignment both in the laboratory and classroom setting resulted in a range of 7 to 11 male participants and 14 to 17 female participants in each of the 12 conditions.

Each participant first was asked to read and sign a consent form (Appendix A) that informed them that their participation was completely voluntary, that they could withdraw at anytime without penalty, and that the trial transcript involved allegations of child sexual abuse. The informed consent was collected separately from the questionnaire package to maintain confidentiality and anonymity of the participants. Following the informed consent, participants were asked to read the trial transcript and to carefully consider all the testimonies presented. They then completed the questionnaire package consisting of the credibility ratings form, the verdict and verdict confidence form, the proposed sentence form (if the defendant was found guilty), the beliefs questionnaire, and the manipulation check form. Participants were explicitly asked to refrain from looking back at the trial transcript when answering the manipulation check form. 
Given that the nature of the simulated trial transcript can be potentially upsetting or anxiety provoking to certain individuals, participants were monitored for any signs of emotional distress throughout their participation. Participation in the study lasted approximately 30 minutes. After completing the study, participants in the laboratory were given a written debriefing form (Appendix $\mathrm{H}$ ) and thanked for their participation. Participants in the classroom setting were verbally debriefed (see Appendix I) and the written debriefing forms were also made available to those who wanted more information. 


\section{Results}

\section{Preliminary Analyses}

Gender. Although the effect of mock juror gender was not specifically investigated in the present study, preliminary analyses were conducted to assess whether the higher ratio of female to male mock jurors in the overall sample and the variation in gender distribution across the different conditions had an impact on the dependent variables, given previous findings on the relationship between gender and juror decisions (e.g., some studies have indicated that females were more likely than males to vote for conviction; see Schutte \& Hosch, 1997, for a review). For mock jurors' guilt ratings for the defendant on a continuous scale, a univariate analysis of variance (ANOVA) revealed a significant main effect for gender, $F(1,293)=10.94, p=.001$, partial $\eta^{2}=.04$. Specifically, female mock jurors gave the defendant significantly higher guilt ratings $(M$ $=59.63, S D=29.20)$ compared to male mock jurors $(M=47.64, S D=31.03)$. A chisquare analysis conducted on dichotomous verdict choices also revealed a significant relationship between gender and verdict, with a significantly greater proportion of females $(120 / 189=0.63)$ compared to males $(41 / 106=0.39)$ finding the defendant guilty than not guilty, $\chi^{2}(1, N=295)=16.87, p<.001$. No effects of gender were found for the rest of the dependent variables (i.e., verdict confidence, credibility ratings for the complainant and defendant, and sentence term recommendation). Given that gender was neither balanced for the overall sample nor counterbalanced across conditions (primarily due to the nature of the data collection; i.e., classroom setting), it was controlled for when necessary in subsequent analyses. 
Manipulation check. Manipulation checks in the form of multiple-choice questions were given to participants to assess the salience of the three experimental variables. Only those that were directly relevant to the three factors under investigation (questions 1, 3, and 4) were analyzed for accuracy while the two fillers (questions 2 and 5) were discarded. Ninety-seven percent $(n=274)$ of mock jurors were able to correctly identify the complainant's age in their respective condition as either 12,25 , or 40 years old (age was used as an index of the length of delay). With respect to the relationship between the defendant and the complainant, $100 \%(n=284)$ of mock jurors were able to correctly identify this relationship and indicated that the defendant had either been the uncle or the former soccer coach of the complainant in their condition. In terms of abuse frequency, $99 \%(n=282)$ of mock jurors were able to correctly identify the number of occasions as either once or 12 times in their condition. Eleven participants who neglected to answer the manipulation check form were still included in all subsequent analyses given the high accuracy rates for the relevant manipulation questions. It is possible that most of these participants did not answer the manipulation check form given that it is the last page of the questionnaire package and therefore may have been easily missed. Two participants failed the manipulation check by providing incorrect responses to at least two of the three questions and were removed from the rest of the analyses.

\section{Juror Verdicts}

Continuous verdict. A 3 (length of delay; 2 vs. 15 . vs. 30 years) $\times 2$ (relationship to complainant; uncle vs. soccer coach) $\times 2$ (frequency of the abuse; once vs. 12 times) 
between-subjects analysis of covariance (ANCOVA) was conducted on mock jurors' guilt ratings for the defendant while controlling for mock juror gender. Significant main effects were found for delay, $F(2,282)=3.46, p=.03$, partial $\eta^{2}=.03$, relationship, $F(1$, $282)=5.80, p=.02$, partial $\eta^{2}=.02$, and abuse frequency, $F(1,283)=3.96, p=.047$, partial $\eta^{2}=.01$

Mock jurors' guilt ratings for the defendant were in the expected direction with higher guilt ratings in the shortest delay condition of 2 years $(M=59.19, S D=28.67)$ compared to the $15-(M=57.24, S D=31.09)$ and 30-year $(M=49.49, S D=30.74)$ delay conditions. Post hoc comparisons using Tukey's HSD indicated that the mean difference in guilt ratings between the 2- and 30-year delay conditions approached significance, $p=$ .06 , with mock jurors assigning higher guilt ratings to the defendant when there was a 2 year rather than a 30-year delay. No significant differences in guilt ratings were found between the 2- and 15-year delay conditions $(p=.89)$ and between the 15- and 30-year delay conditions $(p=.16)$. Consistent with the hypothesis for complainant-defendant relationship, mock jurors gave significantly higher guilt ratings when the defendant was described as the uncle $(M=59.26, S D=29.37)$ rather than the soccer coach $(M=51.36$, $S D=30.94)$. Further, as expected, mock jurors assigned significantly higher guilt ratings when the abuse was perpetrated 12 times $(M=58.78, S D=29.02)$ rather than once $(M=$ $51.89, S D=31.37$ ). See Table 1 for a summary of mock jurors' mean guilt ratings for the defendant as a function of delay, relationship, and abuse frequency.

The latter two significant main effects were qualified by a significant relationship by frequency interaction, $F(1,282)=5.21, p=.02$, partial $\eta^{2}=.02$. Follow-up simple 


\section{Table 1}

Mean (SD) guilt ratings as a function length of delay, complainant-defendant relationship, and frequency of the abuse.

Guilt Ratings

Length of Delay

2 years

$59.19(28.67)$

15 years

$57.24(31.09)$

30 years

$49.49(30.74)$

Complainant-Defendant Relationship

Uncle

$59.26(29.37)$

Soccer Coach

$51.36(30.94)$

Frequency of the Abuse

Once

$51.89(31.37)$

12 times

$58.78(29.02)$ 
main effects analysis indicated that mock jurors rendered significantly higher guilt ratings when the defendant was described as the uncle $(M=59.86, S D=27.62)$ rather than soccer coach $(M=43.92, S D=33.01)$, but only when the abuse was perpetrated once rather than 12 times, $F(1,291)=9.30, p=.003$, partial $\eta^{2}=.03$ (see Figure 1 ). No other significant interaction effects were found.

Dichotomous verdict. Both loglinear (logit) and logistic regression analyses were conducted on dichotomous verdict choices given that the two provide different information. Specifically, a loglinear (logit) analysis would reveal cause and effect relationships between the independent variables (i.e., delay, relationship, and frequency) and the dependent variable (i.e., dichotomous verdict). On the other hand, a logistic regression analysis involves predictions or likelihood ratios and thus would be able to indicate whether dichotomous verdict could be reliably predicted by the same independent variables (or, in logistic regression terms, predictor variables).

A loglinear (logit) analysis and subsequent $z$ tests on individual parameter estimates were conducted to investigate the influence of length of delay, complainantdefendant relationship, frequency of the abuse, and mock juror gender on mock jurors' dichotomous verdict choices (guilty vs. not guilty). No significant main effects were found for delay $(z=1.18, n s)$, relationship $(z=-.52, n s)$, frequency $(z=-.18, n s)$, and juror gender $(z=-.819, n s)$, and there were no significant interactions.

A logistic regression analysis also was performed in which the dichotomous verdict choice (coded as 0 for not guilty and 1 for guilty) was regressed on the following variables: delay, relationship, frequency, and mock juror gender. All possible interactions 


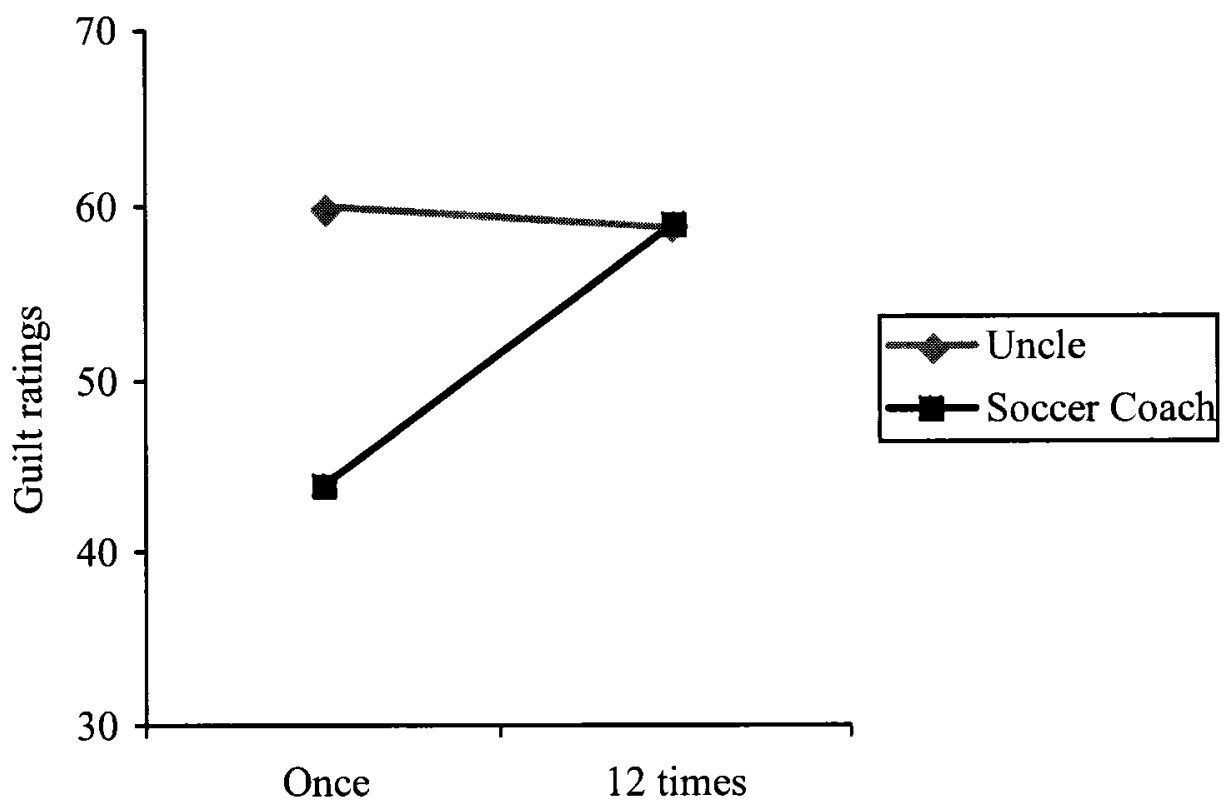

Frequency

Figure 1. Interaction plot showing mean guilt ratings for the defendant as a function of complainant-defendant relationship and frequency of the abuse. 
between the three main factors were also included and all variables were simultaneously entered into the model. The full model was significant, $\chi^{2}(12, N=295)=34.92, p<.001$, and the Hosmer and Lemeshow test revealed a good fit between the data and the model (goodness of fit $\chi^{2}=2.36, d f=8, p=.97$ ). Using the Wald test of significance, only gender was found to reliably predict a guilty verdict. Specifically, male mock jurors reduce the odds of a guilty verdict by approximately $65 \%$ in comparison to female mock jurors (odds ratio ${ }^{9}[\mathrm{OR}]=.34$ ). The results from the logistic regression are presented in Table 2.

\section{Verdict Confidence}

A 3 (length of delay; 2 vs. 15 vs. 30 years) $\times 2$ (complainant-defendant relationship; uncle vs. soccer coach) $\times 2$ (frequency of the abuse; 1 vs. 12 times) between-subjects ANOVA on mock jurors' verdict confidence ratings revealed significant main effects for relationship, $F(1,283)=12.41, p<.001$, partial $\eta^{2}=.04$, and abuse frequency, $F(1,283)=4.71, p=.03$, partial $\eta^{2}=.02$. As seen in Figures 2 and 3 , mock jurors were significantly more confident in their verdict when the defendant was described as the uncle $(M=5.14, S D=1.34)$ rather than the soccer coach $(M=4.50, S D$ $=1.76)$ and as expected, when the abuse was perpetrated 12 times $(M=5.02, S D=1.40)$ rather than once $(M=4.62, S D=1.75)$. No other significant main effects or interactions were found.

\footnotetext{
${ }^{9}$ An odds ratio (OR) greater than 1 is indicative of greater odds for the predicted outcome (i.e., guilty verdict) while an odds ratio less than 1 is indicative of lower odds for the predicted outcome.
} 
Table 2

Logistic regression predicting verdict from length of delay, complainant-defendant relationship, abuse frequency, and mock juror gender.

\begin{tabular}{|c|c|c|c|c|c|}
\hline Variables & $\beta$ & $S E$ & Wald & Sig. $(p)$ & $\begin{array}{l}\text { Odds } \\
\text { ratio }\end{array}$ \\
\hline \multicolumn{6}{|l|}{ Delay } \\
\hline 2 years & .989 & .623 & 2.52 & .11 & 2.69 \\
\hline 15 years & .738 & .614 & 1.44 & .23 & 2.09 \\
\hline 30 years $^{\mathrm{a}}$ & $0^{*}$ & & & & \\
\hline \multicolumn{6}{|l|}{ Relationship } \\
\hline Uncle & -.31 & .60 & .27 & .60 & .73 \\
\hline Soccer Coach ${ }^{\mathrm{a}}$ & $0^{*}$ & & & & \\
\hline \multicolumn{6}{|l|}{ Frequency } \\
\hline Once & -.27 & .59 & .21 & .65 & .76 \\
\hline 12 times $^{\mathrm{a}}$ & $0^{*}$ & & & & \\
\hline \multicolumn{6}{|l|}{ Gender } \\
\hline Male & -1.07 & .26 & 16.69 & $<.001$ & .34 \\
\hline Female $^{\mathrm{a}}$ & $0^{*}$ & & & & \\
\hline \multicolumn{6}{|l|}{ Interactions $^{b}$} \\
\hline Delay (1) by Relationship & .01 & .87 & .00 & .99 & 1.01 \\
\hline Delay (2) by Relationship & .45 & .87 & .27 & .60 & 1.57 \\
\hline Delay (1) by Frequency & -.81 & .86 & .88 & .35 & .45 \\
\hline Delay (2) by Frequency & -1.05 & .86 & 1.50 & .22 & .35 \\
\hline Relationship by Frequency & 1.37 & .85 & 2.56 & .11 & 3.93 \\
\hline \multicolumn{6}{|l|}{ Delay (1) by Relationship by } \\
\hline Frequency & -1.12 & 1.22 & .86 & .36 & .33 \\
\hline \multicolumn{6}{|l|}{ Delay (2) by Relationship by } \\
\hline Frequency & -.80 & 1.22 & .43 & .52 & .45 \\
\hline
\end{tabular}

Note. $S E=$ Standard Error. ${ }^{\text {a }}$ reference category (coded as 0 ) for each predictor variable.

${ }^{\mathrm{b}}$ Delay $(1=2$ years, $2=15$ years $)$.

* This parameter is set to zero because it is redundant. 


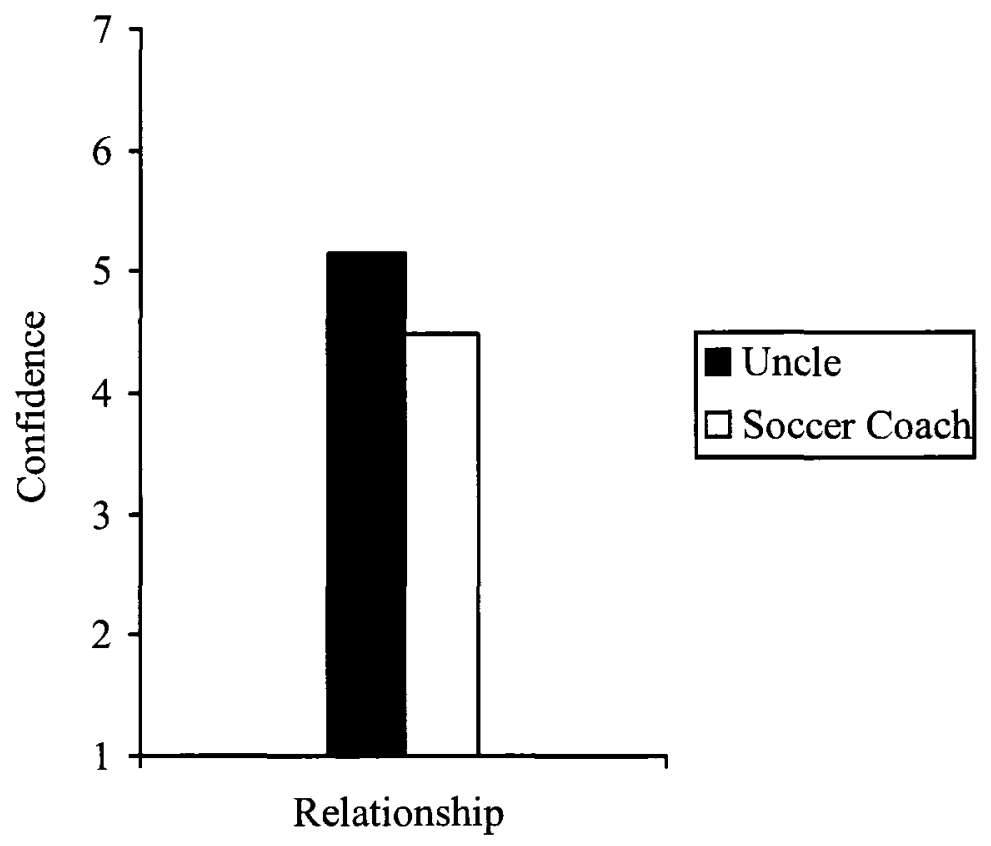

Figure 2. Mock jurors' mean verdict confidence ratings as a function of complainant-defendant relationship.

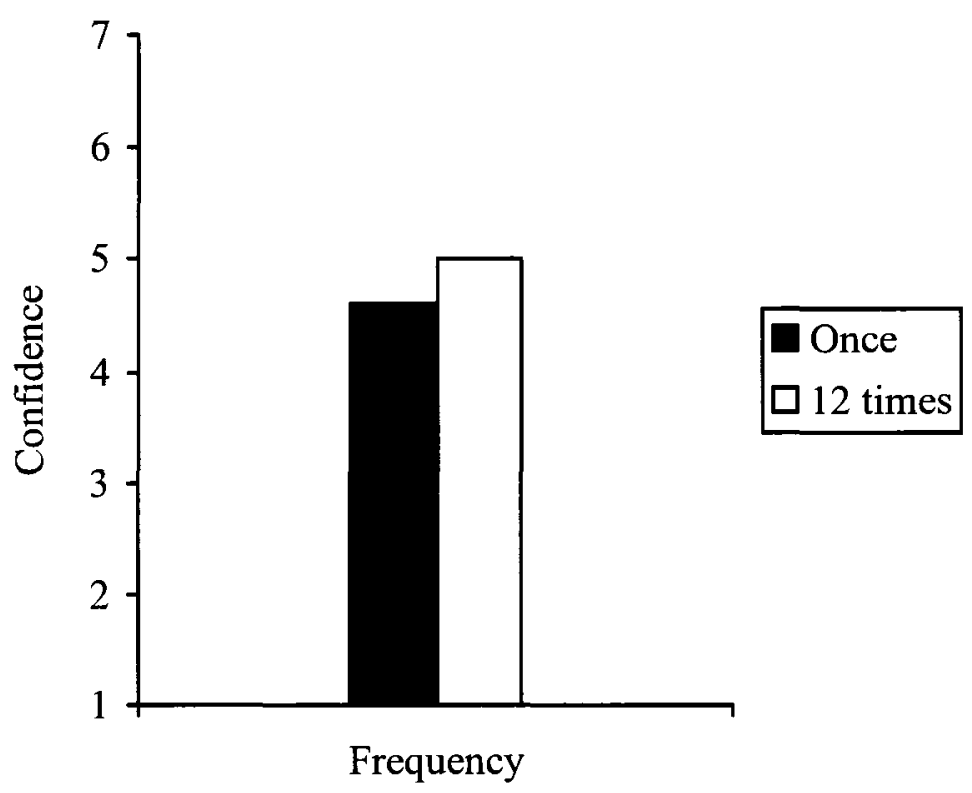

Figure 3. Mock jurors' mean verdict confidence ratings as a function of frequency of the abuse. 


\section{Sentence Recommendation}

For the 161 mock jurors who rendered a guilty verdict (55\% of overall sample), a recommended sentence term from a minimum of 45 days to a maximum of 10 years (Criminal Code, 1985) was requested. An ordinal logistic regression analysis was conducted with delay, relationship, and abuse frequency as predictor variables and the ordered-response measure for sentence term recommendation as the dependent variable (i.e., $1=45$ days, $2=2-11$ months, $3=1-2$ years, $4=3-4$ years, $5=5=6$ years, $6=7-8$ years, $7=9-10$ years). All possible two- and three-way interactions were also included in the model. All variables and interactions were entered simultaneously. The analysis indicated that the full model was significant, $\chi^{2}(11, N=161)=21.59, p=.03$, and provided a good fit to the data, (goodness of fit $\chi^{2}=61.01, d f=55, p=.27$ ). Table 3 displays the Wald coefficients and significance levels for each predictor variable and their respective interactions. Length of delay was found to significantly predict sentence recommendations; the odds of longer sentence term recommendations are 4.81 times more likely in the shortest delay condition of 2 years. Relationship, frequency, and all interactions between the predictor variables did not reliably predict sentence recommendations (all Walds $\leq 2.81, p \mathrm{~s} \geq .09$ ).

\section{Credibility Ratings}

Complainant credibility. The overall credibility of the complainant was evaluated based on three questions that asked mock jurors to rate the complainant on three different dimensions of credibility (i.e., believability, memory reliability, and memory accuracy). 
Table 3

Logistic regression predicting sentence term recommendation from length of delay, complainant-defendant relationship, and abuse frequency.

\begin{tabular}{|c|c|c|c|c|c|}
\hline Variables & $\beta$ & $S E$ & Wald & Sig. $(p)$ & $\begin{array}{l}\text { Odds } \\
\text { ratio }\end{array}$ \\
\hline \multicolumn{6}{|l|}{ Delay } \\
\hline 2 years & 1.57 & .68 & 5.41 & .02 & 4.81 \\
\hline 15 years & -0.35 & .68 & .26 & .61 & .70 \\
\hline 30 years $^{\mathrm{a}}$ & $0^{*}$ & & & & \\
\hline \multicolumn{6}{|l|}{ Relationship } \\
\hline Uncle & -0.72 & .81 & .80 & .37 & .49 \\
\hline Soccer Coach ${ }^{\mathrm{a}}$ & $0^{*}$ & & & & \\
\hline \multicolumn{6}{|l|}{ Frequency } \\
\hline Once & 0.05 & .73 & .01 & .94 & 1.05 \\
\hline 12 times $^{\mathrm{a}}$ & $0^{*}$ & & & & \\
\hline \multicolumn{6}{|l|}{ Interactions ${ }^{b}$} \\
\hline Delay (1) by Relationship & -0.11 & 1.02 & .01 & .92 & .90 \\
\hline Delay (2) by Relationship & 1.72 & 1.03 & 2.81 & .09 & 5.58 \\
\hline Delay (1) by Frequency & -0.83 & 1.60 & .89 & .30 & .11 \\
\hline Delay (2) by Frequency & 0.40 & 1.04 & .15 & .70 & 1.49 \\
\hline Relationship by Frequency & 0.35 & 1.06 & .11 & .74 & 1.42 \\
\hline $\begin{array}{l}\text { Delay (1) by Relationship by } \\
\text { Frequency }\end{array}$ & 0.60 & 1.46 & .17 & .68 & 1.82 \\
\hline $\begin{array}{l}\text { Delay (2) by Relationship by } \\
\text { Frequency }\end{array}$ & -2.02 & 1.46 & 1.93 & .17 & .13 \\
\hline
\end{tabular}

Note. $S E=$ Standard Error. ${ }^{\text {a }}$ reference category (coded as 0 ) for each predictor variable.

${ }^{\mathrm{b}}$ Delay $(1=2$ years, $2=15$ years $)$.

* This parameter is set to zero because it is redundant. 
Correlations between the three questions are presented in Table 4. Given the significant correlations, a composite score for complainant credibility was calculated (Cronbach's $\alpha$ $=.88)$. A 3 (length of delay) $\times 2$ (complainant-defendant relationship) $\times 2$ (frequency of the abuse) between-subjects ANOVA was then conducted on the overall complainant credibility score. No significant main effects were found for delay, $F(2,282)=0.50, p=$ .61 , partial $\eta^{2}=.00$, relationship, $F(1,282)=0.15, p=.70$, partial $\eta^{2}=.00$, and abuse frequency, $F(1,282)=1.63, p=.20$, partial $\eta^{2}=.01$, and there were no significant twoor three-way interactions.

Table 4

Correlations between the three questions assessing the overall credibility of the complainant.

$\mathrm{BC} \quad \mathrm{RC} \quad \mathrm{AC}$

Believability of the complainant $(\mathrm{BC})$

$1.66^{*} \quad .63^{*}$

Memory reliability of the complainant (RC)

$1.83^{*}$

Accuracy of the complainant (AC) $\overline{* p}<.01$.

Defendant credibility. The overall credibility of the defendant was evaluated based on three questions that asked mock jurors to rate the defendant on three different dimensions of credibility (i.e., believability, memory reliability, and memory accuracy). 
Correlations between the three questions are presented in Table 5. Given the significant correlations, a composite score for defendant credibility was calculated (Cronbach's $\alpha=$ .85 ). A 3 (length of delay) $\times 2$ (complainant-defendant relationship) $\times 2$ (frequency of the abuse) between-subjects ANOVA was then conducted on the overall defendant credibility score. No significant main effects were found for delay, $F(2,283)=1.10, p=$ .33 , partial $\eta^{2}=.01$, relationship, $F(1,283)=0.07, p=.79$, partial $\eta^{2}=.00$, and abuse frequency, $F(1,283)=1.74, p=.19$, partial $\eta^{2}=.01$, and there were no significant twoor three-way interactions.

\section{Table 5}

Correlations between the three questions assessing the overall credibility of the defendant.

\begin{tabular}{lccc}
\hline & BD & RD & AD \\
\hline Believability of the defendant (BD) & 1 & $.62^{*}$ & $.64^{*}$ \\
Memory reliability of the defendant (RD) & 1 & $.70^{*}$ \\
Accuracy of the defendant (AD) & & 1 \\
$*_{p<.01 .}$ &
\end{tabular}

\section{Personal Beliefs and Verdict}

Two types of analyses were conducted to explore the extent to which mock jurors' preexisting beliefs affected their rendered verdicts in accordance with the Story 
Model of jury decision-making (Pennington \& Hastie, 1981, 1986). The first involved a logistic regression analysis that examined the association between dichotomous verdict choice (guilty vs. not guilty) and the 13 questions from the Beliefs Questionnaire. The second analysis involved an exploratory analysis of mock jurors' answers to an openended question that asked them to indicate what factors they considered in reaching their verdict. This was intended to supplement the findings from the Beliefs Questionnaire and specifically investigated whether any of the three factors of interest (i.e., delay, relationship, and abuse frequency) were explicitly specified by mock jurors as reason(s) for their verdict decisions. Alternatively, their answers to the open-ended question also revealed factors other than the experimental variables that affected their decisions.

Beliefs questionnaire. A logistic regression analysis was performed with dichotomous verdict choice (coded as 0 for not guilty and 1 for guilty) as the dependent variable and the 13 questions from the Beliefs Questionnaire and mock juror gender as predictor variables. All variables were entered simultaneously. The full model was significantly reliable, $\chi^{2}(14, N=275)=85.26, p<.001$, and the Hosmer and Lemeshow test revealed a good fit between the data and the model (goodness of fit $\chi^{2}=2.71, d f=8$, $p=.95$ ). The Wald test of significance showed that the coefficients for gender and questions $1,2,11$, and 12 were statistically significant and thus reliably predict a guilty verdict. First, the odds of a guilty verdict are approximately $60 \%$ lower if the mock juror is male rather than female $(\mathrm{OR}=.41)$. Further, a one-point increase in mock jurors' agreement with the statements, "Individuals who delay reporting child sexual abuse are more likely to be lying or to be making up their abusive experience" (i.e., question 1) and 
"Individuals who claim to have been sexually abused as a child cannot remember event details well enough to be reliable witnesses in a court of law" (i.e., question 12), are associated with lower odds of a guilty verdict $(\mathrm{OR}=.61$ and $\mathrm{OR}=.75$, respectively). In contrast, a one-point increase in mock jurors' agreement with the statements, "Child sexual abuse by a family member is less likely to occur than child sexual abuse by a stranger" (i.e., question 2) and "Children who are sexually abused by a trusted adult often have difficulty accepting the abuse is wrong and therefore do not report it right away" (i.e., question 11), are associated with greater odds of a guilty verdict $(\mathrm{OR}=1.35$ and $\mathrm{OR}$ $=1.21$, respectively). None of the other questions assessing mock jurors' beliefs regarding HCSA issues were found to reliably predict guilty verdicts. The results from the logistic regression are presented in Table 6.

Open-ended question. To further evaluate the effects of personal beliefs on verdict decisions, an analysis of mock jurors' responses to the open-ended question was included. Given that mock jurors' responses were examined more for exploratory purposes, only the frequency of responses were analyzed. Two independent raters blind to mock jurors' verdict choices and experimental condition coded the frequency of responses. First, raters independently read a different set of approximately 60 (20\% of total sample) randomly selected cases and transcribed and compiled the reasons given by mock jurors in reaching their final verdict. Raters then met together and compiled a master list of all reasons/factors from their independent lists. Factors were combined across raters when there was clear redundancy and all other factors that were not combined were preserved. A total of 51 verdict reasons were identified (see Appendix J). 
Table 6

Logistic regression predicting verdict from participants' agreement with statements from the Beliefs Questionnaire.

\begin{tabular}{cccccc}
\hline Variables & $\beta$ & $S E$ & Wald & Sig. $(p)$ & Odds ratio \\
\hline Gender & & & & & \\
Male & -.90 & .32 & 7.69 & .006 & .41 \\
Female & $0^{*}$ & & & & \\
Beliefs Questions & & & & & \\
1 & -.50 & .32 & 17.91 & $<.001$ & .61 \\
2 & .30 & .12 & 6.70 & .01 & 1.35 \\
3 & .05 & .12 & .17 & .68 & 1.06 \\
4 & -.26 & .13 & 3.82 & .05 & .77 \\
5 & .15 & .13 & 3.27 & .07 & 1.16 \\
6 & -.03 & .08 & .06 & .80 & .97 \\
7 & .10 & .12 & .61 & .44 & 1.10 \\
8 & .03 & .12 & .11 & .74 & 1.03 \\
9 & -.01 & .08 & .00 & .95 & .99 \\
10 & -.09 & .13 & .34 & .56 & .92 \\
11 & .19 & .15 & 4.00 & .04 & 1.21 \\
12 & -.28 & .10 & 6.58 & .01 & .75 \\
13 & -.03 & .11 & .06 & .81 & .97 \\
& & & & & \\
\hline
\end{tabular}

Note. $S E=$ Standard Error. ${ }^{\text {a }}$ reference category (coded as 0$)$.

* This parameter is set to zero because it is redundant. 
Thirty cases selected at random were then coded and discrepancies in scoring were discussed and a decision was reached on how to code them. The process was repeated until an inter-rater reliability coefficient of .80 was reached. Each rater then used the final coding scheme to independently rate mock jurors' responses for the frequency of each verdict reason.

Most (42\%) mock jurors who rendered a guilty verdict cited the defendant's history of making sexually explicit comments to another young girl, despite a lack of a formal complaint, as the foremost reason that led to their guilty verdict. For mock jurors who found the defendant not guilty, the most cited reason was a lack of evidence against the defendant (cited by $50 \%$ of mock jurors). See Table 7 for the five most frequent reasons given by mock jurors for guilty versus not guilty verdicts.

It is evident that among the three factors specifically investigated in the present study, only time delay had a considerable impact on mock jurors' verdict choices, noted by a majority of mock jurors, regardless of whether they voted guilty or not guilty. Mock jurors who convicted the defendant reasoned that the time delay is evidence for the complainant's accusation given that she would not have come forward now, after several years have elapsed, if the allegation(s) was/were in fact not true; on the other hand, mock jurors who acquitted the defendant viewed the time delay to reporting as evidence against the complainant, often stating that the time delay raises suspicions about the veracity of the complainant's allegations (see number 12, Appendix J). In terms of abuse frequency, only a few jurors $(n=6)$ mentioned this as a reason for their verdict choice. When it was mentioned, mock jurors referred to the single occurrence rather than the 


\section{Table 7}

Frequency $(\%)$ of most cited responses to the open-ended question assessing participants' reasons for verdict choice.

Guilty $(n=149)^{\mathrm{b}}$

Defendant's history (despite lack of formal complaint)

Complainant did not have a motive to lie

$44(30 \%)$

Lack of evidence proving defendant's innocence

$36(24 \%)$

Time delay

$34(23 \%)$

Defendant was not convincing

$24(16 \%)$

Not Guilty $(n=122)^{\mathrm{b}}$

Lack of evidence against the defendant

$62(50 \%)$

Time delay

$49(40 \%)$

Reasonable doubt

$48(39 \%)$

A case of "he-said/she-said"

$22(18 \%)$

Complainant was not convincing

$19(15 \%)$

\footnotetext{
${ }^{a}$ Percentages do not add up to 100 given that some participants gave more than one answer.

${ }^{\mathrm{b}}$ Sample sizes for both groups are lower than the original $(n=161$ for guilty and $n=134$ for not guilty) since 12 participants in each group failed to answer the open-ended question.
} 
multiple occurrence of abuse as having an impact on their not guilty verdict. Lastly, the complainant-defendant relationship was not explicitly specified by mock jurors as affecting their verdict. 


\section{Discussion}

The present study investigated the effects of length of delay, complainantdefendant relationship, and frequency of the abuse on the adjudication of historic child sexual abuse cases involving continuous memories. The primary goal of the present study was to address a lack of research on how these factors affect juror decisions. The present study further aimed to narrow the gap between research on HCSA and actual cases encountered by the legal system by investigating how jurors perceived HCSA cases involving continuous rather than repressed memories of the abuse. The study was conducted within the theoretical framework of the Story Model of jury decision-making (Pennington \& Hastie, 1981, 1986) and hence, an exploratory analysis of how mock jurors' preexisting beliefs might predict rendered verdicts also was included.

\section{The Effects of Mock Juror Gender}

Numerous studies have investigated the effects of mock juror gender on CSA cases with relatively consistent results; compared to male mock jurors, females were typically found to assign higher guilt ratings and lower credibility ratings to the defendant and higher credibility ratings to the complainant (Schutte \& Hosch, 1997). Despite the plethora of such studies however, some researchers (e.g., Bottoms, 1993) have found that mock jurors' attitudes and beliefs were better predictors of their perceptions of CSA complainants and defendants, and that these attitudes, rather than juror gender itself, accounted for the apparent gender differences. For instance, Bottoms (1993) found that men who were more empathic toward child victims of CSA and who 
held attitudes relevant to child abuse cases similar to those that were often associated with women (e.g., having pro-feminist views or conservative attitudes toward sex) tended to be more pro-victim; in contrast, women who were less empathic and who held relevant attitudes similar to those that were often associated with men (e.g., attributing responsibility to rape victims) were less likely to be pro-victim.

From a practical perspective, Read et al. (2006) contend that research on juror gender may hold greater significance only in jurisdictions that offer an extended opportunity for jury selection or where real jurors may be allowed to give a post-trial interview. Such opportunities would shed light on how well current research findings concerning the mock juror gender-verdict relationship are representative of verdicts rendered by real jurors. However, in Canada, the opportunity to question potential jurors during the voir dire is significantly restricted and post-trial interviews of jurors are illegal; indeed, jurors are forbidden by Canadian law to describe the content of their deliberations or other facts of a case that were not disclosed in open court (Read et al., 2006). Further, as Huntley and Costanzo (2003) indicated, even researchers contributing to the field of trial consulting in the United States admitted that selecting jurors on the basis of juror profiles (which are primarily based on demographic information such as gender) were "less than optimal," which, consequently, led the majority of trial consulting firms to extend their services beyond advising on the jury selection phase of a trial (p. 31).

For these reasons, the present study did not include a direct investigation of the effects of mock juror gender on the dependent variables. However, the potential 
confounding effects of juror gender were taken into consideration in order to fully isolate the effects of the three main factors of interest, in the case that it did have an effect, particularly in view of the unequal proportion of female to male mock jurors who participated in the present study. Gender was found to have an effect on two of the five dependent variables (i.e., the continuous guilt ratings and dichotomous verdict choices rendered by mock jurors). As such, any subsequent analyses that involved these verdict decisions included gender as a covariate.

Of note, as well, is the significant result that verdict outcome (guilty vs. not guilty) could be reliably predicted by mock juror gender. Specifically, it was found that males were significantly less likely to vote for conviction compared to female mock jurors. This is in line with current research on the relationship between juror gender and rendered verdicts discussed above (e.g., Schutte \& Hosch, 1997).

\section{Manipulation Check}

Overall, the manipulation check was successful, with mock jurors' accuracy rates ranging from $97 \%$ to $100 \%$ for the three factors. In terms of length of delay, mock jurors were asked to indicate the age of the complainant at the time of the trial, given that this was used as an index for the delay to reporting. This resulted in a $97 \%$ accuracy rate across conditions. A closer inspection of the responses of inaccurate jurors $(n=10)$ indicated the possibility that jurors in the 30 -year delay condition might have been confused about the 30-year delay and the complainant age of 40 years at the time of the trial since one choice was "30 years old" (incorrect) and another choice was "40 years 
old" (correct). This possibility was partially confirmed by mock jurors' responses to the open-ended question assessing factors that affected their verdict choices. Some mock jurors $(n=4)$ actually referred to the 30 -year delay in these responses but still chose an age of 30 years old in the manipulation check. It is possible then that if a different age other than 30 years were presented as an alternative choice, the accuracy rate for this particular question would be higher. Nonetheless, the $97 \%$ accuracy rate was still impressive and indicated that the vast majority of mock jurors were aware of the length of delay involved in the case.

The questions assessing the complainant-defendant relationship and frequency of the abuse had accuracy rates of $100 \%$ and $99 \%$ respectively, indicating that mock jurors were aware of the nature of the relationship between the complainant and defendant and the abuse frequency in their conditions.

Length of Delay

Consistent with the first hypothesis, mock jurors gave the defendant significantly higher guilt ratings when there were shorter (i.e., 2 years) compared to longer delays (i.e., 15 or 30 years). This finding is consistent with previous studies which indicated that any type of delay resulted in either less decisions for the plaintiff in mock civil cases (e.g., Golding, Sanchez et al., 1999) or lower guilt ratings for the defendant in mock criminal cases (e.g., Golding et al., 1995, Experiment 2; Sugarman \& Boney-McCoy, 1997). Length of delay also was found to significantly predict sentence term recommendations, with lengthier sentences associated with the shortest delay condition. 
It is reasonable to expect that any delay to reporting child sexual abuse is a disadvantage to HCSA complainants given factors that are typically associated with the passage of time (e.g., loss and/or lack of evidence or witnesses, memory decay, etc.). In the present study, even though mock jurors might not have questioned the veracity of the CSA allegation itself, they appeared to be less willing to accept supporting evidence (i.e., the complainant's memory report) that reflected longer time delays, as demonstrated by the finding that the defendants in the 15- and 30-year delay conditions were found to be less culpable than the defendant in the 2-year delay condition.

It is noteworthy that the significantly greater guilt attributed to the defendant in the shortest delay condition was not reflected in the dichotomous verdicts rendered by mock jurors (only $55 \%$ voted for conviction). As noted previously, the standard of proof in criminal trials requires jurors to find the defendant guilty "beyond all reasonable doubt." The non-significant findings might therefore reflect mock jurors' hesitation to render an absolute verdict of either not guilty or guilty if, for instance, they did not rate the defendant as either $0 \%$ or $100 \%$ guilty on the continuous scale (e.g., some mock jurors gave an $80 \%$ guilt rating and subsequently voted not guilty). This was partially supported by the results from the exploratory analysis of mock jurors' reasons for verdict choices that indicated that a lack of evidence against the defendant (i.e., a cause for reasonable doubt) was the foremost reason given by mock jurors who voted for an acquittal.

In terms of the effects of time delay on credibility ratings for the complainant and the defendant, it was hypothesized that mock jurors would give higher credibility ratings 
to the complainant and lower credibility ratings to the defendant when there were shorter compared to longer delays (H2). As Loftus (1993) argued, individuals may be more inclined to believe that some degree of confabulation has occurred after longer time delays; consequently, length of delay was expected to affect credibility ratings, especially for the complainant. Unlike previous studies that found significant differences in credibility ratings as a function of delay to reporting (Golding, Sanchez et al., 1999), credibility ratings for both the complainant and defendant in the present study were unaffected by the length of delay. Further, the hypothesized three-way interaction effect of delay, relationship, and abuse frequency on credibility ratings also was not supported. These non-significant findings are surprising given the highly significant effects that these factors had on mock jurors' guilt ratings for the defendant, which implicitly suggest that mock jurors believed the complainant more than the defendant (and vice versa) under certain conditions.

These null findings could be attributed to the ambiguity of the complainant and defendant descriptions in the trial transcript used in the present study. This was intentionally done to make the experimental variables appear more salient, in order for mock jurors to base their decisions on the three factors rather than extenuating factors such as the demeanor or expressed emotions of the complainant or defendant. For instance, Kaufmann, Drevlan, Wessel, Overskeid, and Magnussen (2003) suggested that credibility ratings are strongly influenced by the emotions and behaviors displayed by witnesses rather than the factual content of their testimonies. Despite the fact that mock jurors in their study reported rating the credibility of an alleged rape victim based on the 
content of her testimony, the results of their study indicated otherwise. Their findings could be summarized in the following statement: "it is not what you say that determines credibility, but how you say it" (Kaufmann et al., 2003, p. 30). Thus, in the absence of descriptions of emotional expressions or behaviors in the trial transcript for the present study, mock jurors might have been too uncertain to assign meaningful credibility ratings and therefore, non-significant differences in credibility ratings were found across the different conditions.

\section{Complainant-Defendant Relationship}

The main effect of relationship on mock jurors' guilt ratings for the defendant was significant and in the expected direction, with mock jurors assigning higher guilt ratings to the defendant in a case of intrafamilial abuse (i.e., perpetrated by an uncle) rather than extrafamilial abuse (i.e., perpetrated by a former soccer coach; H3). Moreover, despite the significant interaction between relationship and frequency, guilt ratings for the defendant in a case of intrafamilial abuse remained consistently high, regardless of whether the abuse was perpetrated once or multiple times. In relation, mock

jurors also were found to be more confident in their verdict decisions when the defendant was the uncle rather than the soccer coach. In terms of sentence length, the hypothesis that mock jurors would recommend longer sentences when the defendant was described as the uncle rather than the soccer coach was not supported (H4).

The higher guilt ratings for the uncle were consistent with both Moorthy (1998) and McCoy and Gray (2007) who found higher guilt ratings associated with a case of 
intrafamilial compared to extrafamilial abuse. The significant effect of complainantdefendant relationship on verdict confidence ratings in the present study is a first, given that the previous studies did not find significant differences in confidence ratings as a function of relationship to the alleged victim. The significant findings could be attributed to the nature of the crime itself (i.e., sexual assault) and compounded by the identity of the perpetrator. Specifically, other offenses perpetrated by family members that are not sexual in nature may not cause the same moral outrage as those perpetrated by nonfamily members. For instance, a woman might not report physical assault perpetrated by her husband but might be more likely to report physical assault perpetrated by her neighbor or a stranger. On the other hand, sexual offenses perpetrated by family members may engender greater moral outrage since it represents a greater violation of trust, as Moorthy suggested. In assessing community perceptions of CSA, Bornstein et al. (2007) also found that potential jurors viewed child sexual abuse, in contrast to physical abuse, as more severe and traumatic if perpetrated by a family member.

In the United States, the outrage concerning incest is reflected in the enactment of laws in 47 states that specifically prohibit incest (Bolen, 2001). In Canada, whereas sexual assault carries a maximum sentence of 10 years, incest carries a maximum sentence of 14 years, a punishment comparable to that of sexual assault with a weapon, threats to a third party, or bodily harm (Criminal Code, 1985, s. 272). Moreover, whereas a charge of sexual assault can proceed summarily or by indictment, incest is considered only as an indictable offence (Criminal Code, 1985). Thus, it is possible that the null findings in the present study with respect to the effect of complainant-defendant 
relationship on mock jurors' sentence recommendations might be irrelevant given that the societal taboo concerning incest appears already entrenched in enacted laws. All else being equal, current laws dictate that sexual offenses against children perpetrated by family members are subject to harsher sentences than sexual offenses perpetrated by nonfamily members.

Frequency of the Abuse

Consistent with previous findings (Golding, Sego et al., 1999) it was hypothesized that mock jurors would render higher ratings of guilt when the abuse frequency is 12 rather than 1 (H5). This hypothesis was supported in part. Mock jurors assigned significantly higher guilt ratings to the defendant when the number of assaults was 12 rather than 1 , but only when the defendant was the former soccer coach rather than the uncle. In contrast to the intrafamilal case of CSA that automatically led to higher guilt ratings irrespective of the number of assaults, mock jurors seemed more skeptical of the allegation when the defendant was not related to the complainant given the significant difference in mean guilt ratings for the soccer coach as a function of abuse frequency.

Perhaps mock jurors considered the possibility that there may be differences in the opportunities to abuse afforded by the different relationships (Moorthy, 1998). Specifically, an uncle, being a close relative of the complainant, might be viewed as having more opportunities to groom and subsequently abuse the complainant and thus, might account for the consistently higher guilt ratings, regardless of whether the abuse 
was perpetrated once or 12 times. In contrast, mock jurors might be more skeptical in the soccer coach condition given that this relationship might afford fewer opportunities for the alleged abuse (e.g., soccer season typically lasts only for a few months, after which, the soccer coach-player relationship could be terminated). In such a case, the number of assaults perpetrated might be more influential to mock juror decisions, and hence could explain why significant differences in guilt ratings as a function of abuse frequency was observed only when the defendant was the soccer coach.

In terms of verdict confidence ratings, as expected, mock jurors also were found to be significantly more confident in their verdict decisions when the abuse frequency was 12 rather than 1 (H6). This finding substantiates the assertion of Golding, Sego et al. (1999) that mock jurors appear to hold a "more is worse, more is believable" attitude towards CSA. As mentioned, it is possible that HCSA allegations involving repeated instances of abuse might be perceived by mock jurors as more believable compared to a single occurrence of CSA, given that the complainant would be less likely to have "misunderstood" the situation if the abuse happened more than once. Hence, it was expected that the greater believability associated with greater abuse frequency would lead to greater verdict confidence, as found in the present study.

\section{Personal Beliefs and Verdict Reasons}

The exploratory analysis included in the present study that investigated how mock jurors' personal beliefs might affect rendered verdicts revealed several interesting findings. First, in contrast to the complainant-defendant relationship and frequency of the 
abuse, "time delay" was cited as one of the top five reasons for mock juror verdicts, regardless of whether they voted guilty or not guilty. For those who voted not guilty, the fact that the complainant delayed her reporting of HCSA had adverse effects, with quite a number of mock jurors skeptical about the allegations. Most mock jurors reasoned that the complainant "waited too long" to report the abuse, even in the 2-year delay condition. On the other hand, mock jurors who convicted the defendant also noted time delay as a primary reason for their guilty verdicts, with mock jurors reasoning that the allegation(s) must be true given that the complainant would not have disclosed the abuse after so many years if it was not, in fact, true. Further, a few mock jurors who voted for conviction suggested that the time delay could be indicative of more severe abuse and its resulting trauma, and thus, delay led to increased credibility of the complainant, and consequently, guilty verdicts. This finding is consistent with Bornstein et al. (2007) who found that potential jurors seemed to find alleged victims of more severe abuse as more credible and assume that they would be less likely to fabricate.

Such contradictory rationalizations could be interpreted as evidence of mock jurors engaged in fitting the trial information presented to them with their own personal beliefs (according to the Story Model, 1981, 1986), or, more generally, as indicative of confirmation bias (i.e., a bias that involves an "unwitting molding of facts" to fit one's belief; Nickerson, 1998, p. 175). However, this might also be a reflection of either knowledge or, conversely, a lack of knowledge regarding delayed disclosure of CSA. This explanation was supported by mock jurors' responses to statements dealing with issues of time delay in the Beliefs Questionnaire. Specifically, the more mock jurors 
agreed with the statements that children who delay disclosure are more likely to be lying and that individuals who allege HCSA cannot remember details well enough to be reliable witnesses in court, the more likely they were to acquit the defendant. In contrast, the more they agreed with the statement that children abused by trusted adults often delay disclosure, the more likely they were to convict the defendant.

Perhaps the most surprising reason that emerged from mock jurors' verdict reasons concerns the third most cited reason of those who voted for conviction. In direct contrast to the presumption of innocence, a lack of evidence proving the defendant's innocence (thus, a presumption of guilt) was cited by a quarter of those who voted guilty. Although the description of the judge's instructions to the jury at the beginning of the trial transcript included the standard of proof (i.e., the defendant must be found guilty beyond a reasonable doubt), the "innocent until proven guilty" clause was not included in the transcript. Perhaps if it was explicitly mentioned, significantly fewer mock jurors might cite this reason to justify their rendered guilty verdicts. Alternatively, if mock jurors were explicitly warned through the judge's instructions to the jury (or in the arguments presented by the defense) about the dangers of convicting an innocent individual, mock jurors belief in the "presumption of guilt" might have been attenuated.

\section{Limitations and Future Directions}

There are some limitations that need to be addressed in the present study. A major limitation is the use of individual juror decisions and the lack of jury deliberations. Golding, Bradshaw, Dunlap, and Hodell (2007) have argued that it is quite difficult to 
determine how individual decisions (as is usual in mock juror studies) might translate into group verdicts, which in HCSA cases (i.e., involves a criminal trial) require unanimity among jurors. Thus, the results of the present study must be considered preliminary. It would be useful, however, to utilize the present study as a pilot for a future deliberation study on how HCSA cases are adjudicated.

A second limitation concerns the nature of the sample used (i.e., undergraduate students and predominantly women). The greater proportion of female to male mock jurors could be attributed to the composition of students who typically take psychology classes, as others have indicated (Bornstein et al., 2007). In terms of using undergraduate students, researchers have argued that using a convenience sample of undergraduates, despite being the choice population for most psychological research, might be problematic given that findings might not always generalize to the population as a whole (Diamond, 1997). This issue might be even more relevant to jury research given that actual juries are rarely, if ever at all, comprised of a majority of undergraduate students. In the few studies that have found some differences between a student versus non-student sample (e.g., 5 out of a total of 26 studies), the difference reflected a tendency for student mock jurors to be a "softer touch" (Bornstein, 1999, p.80), with mock jurors more likely to find for criminal defendants; such tendencies might be a reflection of students' greater idealism, education, or liberalism (Sears, 1986, as cited in Bornstein, 1999). Thus, Bornstein (1999) concluded that, given the small significant differences found across studies that compared decisions rendered by student versus non-student samples, the use of student mock jurors is not cause for concern and hence, offers some justification for 
the use of students as mock jurors in the present study. Nevertheless, it would be useful for future research to investigate if similar results from the present study would be found using a community sample.

Another important limitation involves the trial medium - written trial transcripts were used instead of a videotaped or audiotaped mock trial. Although such media might have made the trial scenario more realistic, a significant measure of experimental control is lost in this way. Specifically, it is possible that the performance of the actors, especially in terms of the level of emotions expressed in a videotaped trial, might affect mock jurors' rendered decisions in view of previous findings that not only found that observers imposed less punishment when a victim's emotional reaction was mild rather than severe, but that the victim who displayed mild emotional reactions also generated less sympathy (Nadler \& Rose, 2003). By using a written transcript, the confounding effects of other factors such as expressed emotion were controlled for.

A related limitation concerns the information provided in the transcript. The transcript was intentionally created to reflect a certain ambiguity regarding evidence presented at trial in order to avoid a preponderance of either verdict decision (guilty vs. not guilty). Further, such ambiguity in the general scenario would allow for the factors under investigation to have a greater effect on mock juror decisions instead of being confounded by other variables (e.g., presence of stronger corroborating evidence such as DNA). However, it is possible that the transcript was inadvertently made too ambiguous, as some mock jurors have indicated this verbally or through the open-ended questionnaire. Thus, this might have actually led some mock jurors to "default" to a not 
guilty verdict. For future studies, it might be useful to test the quality of the trial transcripts that will be used, perhaps through a small pilot study, prior to conducting large-scale jury studies.

Lastly, given the interesting findings from the exploratory analyses conducted on mock juror beliefs and how these affected verdict decisions, future studies could expand the Beliefs Questionnaire by increasing the number of questions to more fully investigate how mock jurors' preexisting beliefs account for their decisions in HCSA cases. Similar to Bolen and Scannapieco (1999) who found that the number of screening questions significantly affected the findings from prevalence studies, it is likely that an increase in beliefs statements would present a better picture of how mock jurors reach their verdict decisions by drawing from their personal beliefs regarding HCSA.

\section{Conclusion and Implications}

The present study represents an initial step towards understanding how potential jurors might react to cases of historic child sexual abuse involving continuous memories. The significant findings highlight the importance of timely disclosure in CSA cases given that the length of delay between the alleged abuse and the time of reporting had the greatest impact on the perceived culpability of the defendant and the subsequent sentence term recommendations. Further, the relationship between the complainant and the defendant and the frequency of the abuse proved to be significantly related not only to the perceived culpability of the defendant, but also to the confidence of mock jurors regarding their rendered verdicts. This is important in view of the possibility that 
confidence regarding pre-deliberation verdicts might be a reliable indication of how well individual verdicts survive after jury deliberations. The findings from the present study lead to important practical implications.

First, given the traumatic nature of HCSA and the embarrassment and fear of disbelief that typically plague HCSA victims, the present findings may be helpful to victims when deciding what, if any, legal avenues to pursue against the abuser. There is no question that HCSA victims deserve validation in the form of legal remedies and HCSA perpetrators should be made accountable for their actions. However, in some cases, it is possible that the severe psychological consequences of losing one's case may prove to be too traumatic for the victim. For instance, an HCSA victim who loses his/her case in criminal court may wind up being even more traumatized than if the case was not brought into court at all. The present findings might then help victims decide if they should proceed with a civil suit (at least in jurisdictions where the statute of limitations are tolled or where none exists) rather than pressing criminal charges against the defendant. Further, the present findings might also be useful to legal counsels since they typically consider likely juror decisions in deciding whether or not to prosecute a particular case (i.e., exercise prosecutorial discretion), or for defense attorneys, whether to take a particular case, or whether to proceed with a trial or enter a guilty plea for the defendant. 
References

American Psychological Association. (1998). Final conclusions of the American Psychological Association working group on investigation of memories of childhood abuse. Psychology, Public Policy, and Law, 4, 933-940.

Ashcraft, M. H. (1994). Cognition ( $3^{\text {rd }}$ ed.). Upper Saddle River, NJ: Prentice Hall.

Badgley, R., Allard, H., McCormick, N., Proudfoot, P., Fortin, D., Ogilvie, D., RaeGrant, Q., Celinas, P., Pepin, L., \& Sutherland, S. (Committee on Sexual Offences Against Children and Youth). (1984). Sexual offences against children (Vol. 1). Ottawa, ON: Canadian Government Publishing Centre.

Bolen, R. M. (2001). Child sexual abuse: Its scope and our failure. Boston, MA: Kluwer Academic Publishers.

Bolen, R. M., \& Scannapieco, M. (1999). Prevalence of child sexual abuse: A corrective metanalysis. Social Service Review, 73, 281-313.

Bornstein, B. H. (1999). The ecological validity of jury simulations: Is the jury still out? Law and Human Behavior, 23, 75-92.

Bornstein, B. H., Kaplan, D. L., \& Perry, A. R. (2007). Child abuse in the eyes of the beholder: Lay perceptions of child sexual and physical abuse. Child Abuse and Neglect, 31, 375-391.

Bottoms, B. L. (1993). Individual differences in perceptions of child sexual assault victims. In G. S. Goodman and B. L. Bottoms, Child victims, child witnesses: Understanding and improving testimony, (pp.229-261). New York: Guilford Press. 
Bottoms, B. L., \& Goodman, G. S. (1994). Perceptions of children's credibility in sexual assault cases. Journal of Applied Social Psychology, 24, 702-732.

Brown, R. D., Goldstein, E., \& Bjorklund, D. F. (2000). The history and xeitgeist of the repressed-false-memory debate: Scientific sociological perspectives on suggestibility and childhood memory. In D. F. Bjorklund (Ed.), False-memory creation in children and adults: Theory, research, and implications, (pp. 1-30). Mahwah, NJ, US: Lawrence Erlbaum.

Ceci, S. J., \& Bruck, M. (1993). The suggestibility of children's recollections: An historical review and synthesis. Psychological Bulletin, 113, 403-439.

Chaffin, M. (2006). The changing focus of child maltreatment research and practice within psychology. Journal of Social Issues, 62, 663-684.

Clark, H. L., \& Nightingale, N. N. (1997). When jurors consider recovered memory cases: Effects of victim and juror gender. Journal of Offender Rehabilitation, 25 , 87-104.

Connolly, D. A., \& Read. J. D. (2006). Delayed prosecution of historic child sexual abuse: Analyses of 2064 Canadian Criminal Complaints. Law and Human Behavior, 30, 409-434.

Connolly, D. A., \& Read. J. D. (2003). Remembering historical child sexual abuse. Criminal Law Quarterly, 47, 438-480.

Courtois, C. A. (1988). Healing the incest wound: Adult survivors in therapy. New York: Norton.

Criminal Code, R. S. C. 1985. 
Davis, P. J., \& Schwartz, G. E. (1987). Repression and the inaccessibility of affective memories. Journal of Personality and Social Psychology, 52, 155-162.

Degroot, J. M., Kennedy, S., Rodin, G., \& McVey, G. (1992). Correlates of sexual abuse in women with anorexia nervosa and bulimia nervosa. Canadian Journal of Psychiatry, 37, 517-518.

Department of Justice Canada. (2006). Child abuse: A fact sheet from the Department of Justice Canada. Retrieved on November 28, 2006, from the DOJ Canada website Access: http://www.doj.ca/en/ps/fm/childafs.html

Diamond, S. S. (1997). Illuminations and shadows from jury simulations. Law and Human Behavior, 21, 561-571.

Fergusson, D. M., \& Mullen, P. E. (1999) Child sexual abuse: An evidence based perspective. Thousand Oak, CA: Sage Publications.

Finkelhor, D. (1994). Current information on the scope and nature of sexual abuse. The Future of Children, 4, 31-53.

Finkelhor, D., Hotaling, G., Lewis, I. A., \& Smith, C. (1990). Sexual abuse in a national survey of adult men and women: Prevalence, characteristics, and risk factors. Child Abuse and Neglect, 14, 19-28.

Friedrich, W. N., Urquiza, A. J., \& Beilke, R. L. (1986). Behavior problems in sexually abused young children. Journal of Pediatric Psychology, 11, 47-57.

Gabora, N. J., Spanos, N. P., \& Joab, A. (1993). The effects of complainant age and expert psychological testimony in a simulated child sexual abuse trial. Law and Human Behavior, 17, 103-119. 
Golding, J. M., Bradshaw, G. S., Dunlap, E. E., \& Hodell, E. C. (2007). The impact of mock jury gender composition on deliberations and convictions rates in a child sexual assault trial. Child Maltreatment, 12, 182-190.

Golding, J. M., Sanchez, R. P., \& Sego, S. A. (1999). Brief research report: Age factors affecting the believability of repressed memories of child sexual assault. Law and Human Behavior, 23, 257-268.

Golding, J. M., Sego, S. A., \& Sanchez, R. P. (1999). The effect of multiple childhood sexual assaults on mock jurors' perceptions of repressed memories. Behavioral Sciences and the Law, 17, 483-493.

Golding, J. M., Sego, S. A., Sanchez, R. P., \& Hasemann, D. (1995). The believability of repressed memories. Law and Human Behavior, 19, 569-592.

Goodman-Brown, T. B., Edelstein, R. S., Goodman, G. S., Jones, D. P. H., \& Gordon, D. S. (2003). Why children tell: a model of children's disclosure of sexual abuse. Child Abuse \& Neglect, 27, 525-540.

Grayston, A. D., \& DeLuca, R. V. (1999). Female perpetrators of child sexual abuse: A review of the clinical and empirical literature. Aggression and Violent Behavior, $4,1,93-106$.

Griffith, J. D., Libkuman, T. M., Kazen, J., \& Shafir, Z. (1999). Repressed memories in the courtroom: Trial characteristics affecting mock jurors' decision making. American Journal of Forensic Psychology, 17, 5-24. 
Haugaard, J. J., \& Reppucci, N. D. (1988). The sexual abuse of children: A comprehensive guide to current knowledge and intervention strategies. London: Jossey-Bass.

Herman. J. L. (1992) Trauma and recovery. New York: Basic Books.

Herman, J. L., \& Shatzow, E. (1987). Recovery and verification of memories of childhood sexual trauma. Psychoanalytic Psychology, 4, 1-14.

Hershkowitz, I., Lanes, O., \& Lamb, M. E. (2007). Exploring the disclosure patterns of child sexual abuse with alleged victims and their parents. Child Abuse and Neglect, 31, 111-123.

Huntley, J. E., \& Constanzo, M. (2003). Sexual harassment stories: Testing a storymediated model of juror decision-making in civil litigation. Law and Human Behavior, 27, 29-51.

Kaplan, M. F., \& Kemmerick, G. D. (1974). Juror judgment as information integration: Combining evidential and nonevidential information. Journal of Personality and Social Psychology, 30, 493-499.

Kaufmann, G., Drevland, G. C. B., Wessel, E., Overskeid, G., \& Magnussen, S. (2003). The importance of being earnest: Displayed emotions and witness credibility. Applied Cognitive Psychology, 17, 21-34.

Key, H. G., Warren, A. R., \& Ross, D. F. (1996). Perceptions of repressed memories: A reappraisal. Law and Human Behavior, 20, 555-563.

Lamb, S., \& Edgar-Smith, S. (1994). Aspects of disclosure: Mediators of outcome of childhood sexual abuse. Journal of Interpersonal Violence, 9, 307-326. 
Leippe, M. R., \& Romanczyk, A. (1987). Children on the witness stand: A communication/persuasion analysis of jurors' reactions to child witnesses. In S. J. Ceci, M. P. Toglia, \& D. F. Ross (Eds.), Children's eyewitness memory (pp.155177). New York: Springer-Verlag.

Leventhal, J. (1990). Epidemiology of child sexual abuse. In R. K. Oates (ed.), Understanding and managing child sexual abuse (pp.18-41). Sydney: Harcourt.

Lindsay, D. S., Hagen, L., Read, J., D, Wade, K. A., \& Garry, M. (2004). True photographs and false memories. Psychological Science, 15, 149-154.

Lindsay, D. S., \& Read, J. D. (1995). "Memory work" and recovered memories of childhood sexual abuse: Scientific evidence and public, professional, and personal issues. Psychology, Public Policy, and Law, 1, 846-908.

London, K., Bruck, M., Ceci, S. J., \& Shuman, D. W. (2005). Disclosure of child sexual abuse: What does the research tell us about the ways that children tell? Psychology, Public Policy, and Law, 11, 194-226.

Loftus, E. F. (1993). The reality of repressed memories. American Psychologist, 48, 518537.

Loftus, E. F., \& Davis, D. (2006). Recovered memories. Annual Review in Clinical Psychology, 2, 469-98.

Loftus, E. F., Garry, M., \& Feldman, J. (1994). Forgetting sexual trauma: What does it mean when 38\% forget? Journal of Consulting and Clinical Psychology, 62, $1177-1181$.

Loftus, E. F., \& Pickrell, J. E. (1995). The formation of false memories. Psychiatric 
Annals, 25, 720-725.

Loftus, E. F., Weingardt, K. R., \& Hoffman, H. G. (1993). Sleeping memories on trial: Reactions to memories that were previously repressed. Expert Evidence, 2, 51-59. Martin, J., Anderson, J., Romans, S., Mullen, P., \& O'Shea, M. (1993). Asking about child sexual abuse: Methodological implications of a two stage survey. Child Abuse and Neglect, 17, 383-392.

McCoy, M. L., \& Gray, J. M. (2007). The impact of defendant gender and relationship to victim on juror decisions in a child sexual abuse case. Journal of Applied Social Psychology, 37, 1578-1593.

Mian, M., Wehrspann,W., Kaljner-Diamond, H., LeBaron, D., \& Winder, J. (1986). Review of 125 children 6 years of age and under who were sexually abused. Child Abuse \& Neglect, 10, 223-229.

Moorthy, P. C. (1998). The effects of the plaintiff-defendant relationship and judge's instructions on simulated jurors' perceptions of recovered memories for childhood sexual abuse. Dissertation Abstracts International, 58(9-B) (UMI No. 9808227).

Nadler, J., \& Rose, M. (2003). Victim impact testimony and the psychology of punishment. Cornell Law Review, 88, 419.

Nickerson, R. S. (1998) Confirmation bias: A ubiquitous phenomenon in many guises. Review of General Psychology, 2, 175-220.

Nightingale, N. N. (1993). Juror reactions to child witnesses: Factors affecting trial outcome. Law and Human Behavior, 17, 679-694. 
Northcott, M. J., Connolly, D. A., \& Price, H. L. (2005). The effect of age and abuse frequency on the perceived credibility of HCSA victims. Poster presented at the seventh annual meeting of the Northwest Cognition and Memory Conference, Bellingham, Washington.

Olafson, E., Corwin, D. L., \& Summit, R. C. (1993). Modern history of child sexual abuse awareness: Cycles of discovery and suppression. Child Abuse \& Neglect, $17,7-24$.

Pennington, N., \& Hastie, R. (1981). Juror decision-making models: The generalization gap. Psychological Bulletin, 89, 246-287.

Pennington, N., \& Hastie, R. (1986). Evidence evaluation in complex decision-making. Journal of Personality and Social Psychology, 51, 242-258.

Pennington, N., \& Hastie, R. (1988). Explanation-based decision making: Effects of memory structure on judgment. Journal of Experimental Psychology: Learning, Memory, and Cognition, 14, 521-533.

Pezdek, K., Finger, K., \& Hodge, D. (1997). Planting false childhood memories: The role of event plausibility. Current Directions in Psychological Science, 8, 437-441.

Pezdek, K., \& Hodge, D. (1999). Planting false childhood memories in children: The role of event plausibility. Child Development, 70, 887-895.

Porter, S., Campbell, M., Birt, A.R. \& Woodworth, M. (2003). "He said, she said": A psychological perspective on historical memory evidence in the courtroom. Canadian Psychology, 44, 190-206. 
Read, J. D., Connolly, D. A., \& Welsh, A. (2006). An archival analysis of actual cases of historic child sexual abuse: A comparison of jury and bench trials. Law and Human Behavior, 30, 259-285.

Sas, L. D. (1993). Three years after the verdict. London, Ont., Canada: London Family Court Clinic Inc.

Sas, L. D., \& Cunningham, A. H. (1995). Tipping the balance to tell the secret: Public discovery of child sexual abuse. London, ON: London Family Court Clinic.

Sauzier, M. (1989). Disclosure of child sexual abuse: For better or worse. Psychiatric Clinics of North America, 12, 455-469.

Schutte, J. W., \& Hosch, H. M. (1997). Gender differences in sexual assault verdicts: A meta-analysis. Journal of Social Behavior and Personality, 12, 759-772.

Smith, D. W., Letourneau, E. J., Saunders, B. E., Kilpatrick, D. G., Resnick, H. S., \& Best, C. L. (2000). Delay in disclosure of childhood rape: Results from a national survey. Child Abuse \& Neglect, 24, 273-287.

Seymour, F. W. (1996). Memory and childhood abuse: The psychological evidence. Waikato Law Review, 4. Retrieved on September 10, 2006, from the Waikato Law Review website. Access:

http://www.waikato.ac.nz/law/wlr/special_1996/6_seymour.html

Statistics Canada (2003). Immigration, ethnicity, and language in Ottawa: Fast facts from the 2001 census. Ottawa, ON: Statistics Canada.

Stewart, T. L., Whiteside, S. P., \& Golding, J. M. (2000). The effectiveness of expert witnesses in civil trials involving repressed memories of sexual assault. American 
Journal of Forensic Psychology, 18, 27-62.

Sugarman, D. B., \& Boney-McCoy, S. (1997). Impact of expert testimony on the believability of repressed memories. Violence and Victims, 12, 115-126.

Tetford, I. \& Schuller, R. A. (1996). Mock jurors' evaluations of child sexual abuse: The impact of memory recovery and therapeutic intervention. Behavioral Sciences and the Law, 14, 205-218.

Trocme, N., MacLaurin, B., Fallon, B., Daciuk, J., Billingsley, D., Tourigny, M., Mayer, M., Wright, J., Barter, K., Burford, G., Hornick, J., Sullivan, R., \& McKenzie, B. (2005). Canadian incidence study of reported child abuse and neglect: Final report. Ottawa: National Clearinghouse on Family Violence, Health Canada.

Ullman, S. E. (2007). Relationship to perpetrator, disclosure, social reactions, and PTSD symptoms in child sexual abuse survivors. Journal of Child Sexual Abuse, 16, 1936.

U.S. Department of Health and Human Services, Administration on Children, Youth and Families. (2007). Child Maltreatment. Washington, DC: U.S. Government Printing Office.

Wade, K. A., Garry, M., Read, J. D., \& Lindsay, D. S. (2002). A picture is worth a thousand lies: Using false photographs to create false childhood memories. Psychonomic Bulletin \& Review, 9, 597-603.

Williams, L. M. (1994). Recall of childhood trauma: A prospective study of women's memories of child sexual abuse. Journal of Consulting and Clinical Psychology, $62,1167-1176$. 
Young, E. B. (1990). The role of incest issues in relapse. Journal of Psychoactive Drugs, $22,249-258$. 


\author{
Appendix A \\ Informed Consent Form
}

The purpose of an informed consent is to ensure that you understand the purpose of the study and the nature of your involvement. The informed consent must provide sufficient information such that you have the opportunity to determine whether you wish to participate in the study.

Research Title: Jury Decision-Making

Research Personnel: The following individuals are involved in this research project and may be contacted for further information: Charmagne Crescini (Principal Investigator, 520-2600, ext. 3695), Dr. Joanna Pozzulo (Faculty Advisor, 520-2600, ext. 1412), Dr. Janet Mantler (Chair, Carleton University Ethics Committee for Psychological Research, 520-2600, ext. 4173), or Dr. Mary Gick (Chair, Department of Psychology, 520-2600, ext. 2648).

Purpose: The purpose of this study is to gain insight into juror decisions.

Task Requirement: Should you choose to participate in this study, you will be asked to read a trial transcript and answer questions based on what you have read.

Duration and Location: Participation will take approximately 30-45 minutes, and each participant will receive a $1 \%$ credit towards their final mark in PSYC 1001/02. The experimental session will take place in Room 111 in the Social Sciences Research Building at Carleton University.

Potential Risk/Discomfort: The subject matter of the trial involves allegations of child sexual abuse, which could be upsetting to some individuals. Please be reminded that your participation is entirely voluntary, that you may choose not to answer any question, and that you may withdraw from the study at any time without penalty.

Confidentiality/Anonymity: All data gathered in this study are anonymous and confidential and will only be used by the researchers involved in the study. Your name will not appear anywhere on your questionnaire. The consent forms will be kept separate from your responses.

I have read the above form and understand the nature of my participation. My participation is voluntary and I am aware that I may withdraw at anytime. I am aware 
that the data gathered in this study are anonymous and confidential with respect to my personal identity. My signature below indicates that I agree to participate in this study.

Participant's Name:

Researcher's Name:

Participant's Signature:

Researcher's Signature:

Date: 
Appendix B

\section{Trial Transcript}

Judge: Mr. Ferguson has been charged with section 151 of the Criminal Code, Sexual Interference. The Crown has the burden of proving that charge beyond a reasonable doubt. It is your responsibility to listen to all the evidence, to decide the facts, and then to apply the law that I will give you at the end of the trial. The case will begin with opening statements from both the Crown and Defence attorneys. These statements are not evidence, yet summaries of what will be presented in the trial. Following these statements, the Crown and Defence will present and question a number of witnesses, who will subsequently be cross-examined. Please listen to the following arguments carefully. Following the testimonies, you will be asked to make a decision as to whether you find the defendant, Mr. Ferguson, guilty or not guilty of the charge.

The Crown makes their opening statement.

Crown: Mr. John Ferguson is/was the uncle/soccer coach of the complainant, Susan Johnson. Two/Fifteen/Thirty years ago, on March 16, Mr. Ferguson gave Susan a ride home from soccer practice, and they were alone in the car. Mr. Ferguson took advantage of this opportunity and sexually touched 10-year-old Susan Johnson, known in the Criminal Code as sexual interference. Susan pleaded for her uncle/soccer coach to stop, but he would not. The abuse occurred once/12 times within a six-week period, after soccer practice. Mr. Ferguson made Susan promise that this would be a secret kept between just the two of them. He said that no one would believe her anyway if she told and it would just get her in trouble. Ten-year-old Susan felt powerless and afraid at the time and therefore did not disclose details of the abuse until now, 2/15/30 years later. Mr. Ferguson, Susan's uncle/soccer coach, abused his authority to get what he wanted. It is therefore, your duty, as representatives of our community, to seek justice by finding Mr. Ferguson guilty of sexual interference.

The Defence makes their opening statement.

Defence: Mr. Ferguson did not sexually touch Susan Johnson. Yes, it is true that Mr. Ferguson drove Susan home from soccer practice. Yes, they were the only ones in the car. The accusations proposed however, that Mr. Ferguson sexually touched Susan once/12 times during the ride(s) home are completely and utterly false. I'd like to point out that Mr. Ferguson has no criminal record and no past history of any sexual offences. To assume that the sexual touching occurred is preposterous. I trust that you will consider all the information accordingly and find that my client is indeed innocent.

The Crown calls their first witness, a teacher at South Hastings Elementary School. Crown: Please state your name and position for the Court.

Witness: My name is Mr. Matheson and I am a teacher at South Hastings Elementary. Crown: How long have you known Susan Johnson? 
Witness: Let's see, at that time, I was a science teacher for Grades 4 and 5, so I would say that I knew her for a total of 2 years.

Crown: And in these 2 years, has Susan been a known troublemaker?

Witness: No of course not. She achieved good grades, got along with her peers, she was respectful to myself and the other teachers, and was generally a very pleasant girl.

Crown: Did you trust Susan, Mr. Matheson?

Witness: Yes, I did.

Crown: Overall, did you consider Susan as a good student, Mr. Matheson?

Witness: Yes, I did.

Crown: Thank you Mr. Matheson. I have no further questions your honour.

The Defence cross examines the witness.

Defence: Hello Mr. Matheson.

Witness: Hello.

Defence: You said you would not describe Susan as a troublemaker?

Witness: Absolutely not.

Defence: So to your knowledge, Susan had never done anything wrong at school?

Witness: Well I wouldn't say that. I mean, she was a 10-year-old kid; kids sometimes get themselves into trouble.

Defence: Were you aware that Susan was caught lying about her involvement regarding a serious school offence? That she lied about lighting firecrackers on school property?

Witness: Yes I was.

Defence: And how did the school treat this offence?

Witness: Susan and the other students were given detention and their parents were notified.

Defence: No further questions your Honour.

The witness is excused.

The Crown calls their second witness, Susan Johnson and she takes the stand.

Crown: Please state your name and age for the Court.

Witness: My name is Susan Johnson and I am 12/25/40 years old.

Crown: Please tell me what happened on March 16, 2/15/30 years ago.

Witness: Well, soccer practice had just ended and Uncle/Coach John and I got into his car. He was driving me home from soccer practice.

Crown: Was there anyone else in the car with you and Mr. Ferguson?

Witness: No, it was just the two of us.

Crown: And then what happened?

Witness: He said we needed to talk and he parked the car on the street.

Crown: What happened next?

Witness: Well, he um... he got me to pull down my pants (hesitates).

Crown: I know this is hard Susan, but then what happened?

Witness: He made me pull down my pants, and then he started touching me...down there/my genitals. 
Crown: So he touched your vaginal area, is that correct?

Witness: Yes.

Crown: How was he touching you?

Witness: Well, at first he was touching me with his hands. But um... but then he took off his pants, and started rubbing his private area against mine/his penis against my vagina.

Crown: Were you agreeable to doing this?

Witness: No, I didn't want to, but he made me. I told him to stop, but he wouldn't. He just kept telling me to be quiet and I could go home soon.

Crown: Then what happened?

Witness: He told me not to tell anyone, or I would get in a lot of trouble. He started up the car again and finally dropped me off at my house.

Crown: Did you continue getting rides from Mr. Ferguson at the end of soccer practice even after this incident?

Witness: Yes. I was afraid of him so I never told anyone and pretended everything was okay.

Crown: How many times did the abuse occur?

Witness: Only that one time/12 times over 6 weeks.

Crown: Why did you wait $2 / 15 / 30$ years to tell someone about the abuse?

Witness: I was afraid at the time. He kept saying that no one would ever believe me and that I would just be called a liar. I was confused too; I thought maybe it was all my fault. And I was ashamed of what happened and did not want anyone to know. But I remember it clearly. I've never forgotten about what happened then and I always think about it. I don't want this to happen to any other children.

Crown: Thank you Susan. No further questions your Honour.

The Defence cross examines the witness.

Defence: Hi Susan. I just have a few more questions for you. How many times a week did you have soccer practice?

Witness: Twice a week, sometimes three times a week when we have a game coming up.

Defence: Okay, and Mr. Ferguson would always give you a ride home after soccer practice?

Witness: Sometimes. My mother did not get off work until $6 \mathrm{pm}$, so he told her that he could drop me off.

Defence: Tell me, Susan, did your mother pay or give Mr. Ferguson anything in exchange for driving you home?

Witness: No.

Defence: So, Mr. Ferguson was actually doing you and your mother a favour by making sure that you got home safe?

Witness: I guess so... yeah.

Defence: Okay then. Now, you mentioned that you were 10 years old during this time?

Witness: Yes.

Defence: That was a long time ago, wasn't it? 
Witness: Yes.

Defence: Do you remember everything that happened to you when you were 10? Like, what did your mother get you for your $10^{\text {th }}$ birthday?

Crown: Objection! Irrelevant question.

Defence: The question is relevant to understand how clear the witness' memory was 2/15/30 years ago.

Judge: Overruled. Witness, please answer the question.

Witness: Um... I think it was a pink backpack.

Defence: You think? You don't know for sure? (Sarcastic).

Witness: I'm pretty sure, no I'm very sure. It was my favourite backpack.

Defence: Tell me, Susan, you claim that Mr. Ferguson sexually touched you when you were 10 years old?

Witness: Yes.

Defence: Are you sure?

Witness: Yes.

Defence: As sure as you were when I first asked you about your birthday gift?

Crown: Objection! Leading the witness.

Judge: Sustained.

Defence: Now, Susan, if Mr. Ferguson did in fact sexually touch you once/12 times, were you upset about this?

Witness: Yes, of course. I was extremely upset about what happened.

Defence: If you were really upset, how come you didn't tell anyone then? You mentioned that you were afraid no one would believe you, but what about your own mother? You couldn't even tell her?

Witness: I should have, but I was afraid that she might think that I was lying.

Defence: You were afraid that she wouldn't believe you because you've lied before right? About lighting firecrackers at school?

Witness: That has nothing to do with this! This is different -

Defence: Yes or no, Susan!

Witness: Um...yes.

Defence: No further questions, your Honour.

The witness is excused.

The Defence calls their first witness, Mr. Williams.

Defence: Good morning. Please state your name and age for the court.

Witness: My name is Paul Williams and I am 50 years old.

Defence: Mr. Williams, how do you know the defendant, Mr. Ferguson?

Witness: I met Mr. Ferguson during soccer practices and games. My child played on the soccer team at South Hastings Elementary.

Defence: How long have you known him for?

Witness: for 3 years - my child was in the same soccer team for 3 years.

Defence: Tell me, Mr. Williams, have you ever let Mr. Ferguson give your daughter a ride home from soccer practice? 
Witness: Yes, on a few occasions when I wasn't able to pick her up. She and Susan would both get rides home from him.

Defence: "Few" occasions? Can you be more specific?

Witness: I'd say 3 to 4 times.

Defence: And to your knowledge, were there any problems that arose from these 3 or 4 occasions.

Witness: No, no problems at all that I am aware of.

Defence: Mr. Williams, was your daughter ever alone with the defendant, Mr. Ferguson?

Witness: Yes, actually, one time, when Susan was not at practice and I had to work late, my daughter called me to say that she was getting a ride home from John Ferguson.

Defence: And, did this particular occasion occur after March of 2/15/30 years ago?

Witness: Let's see...yes, I think it happened around June. That's when I was really busy with work.

Defence: And did you trust Mr. Ferguson with your child, Mr. Williams?

Witness: Yes, I did.

Defence: Did you have any reason to suspect that he was ever inappropriate with your daughter during the rides home?

Witness: No.

Defence: Thank you, Mr. Williams. No further questions, your Honour.

The Crown cross-examines the witness.

Crown: Hello Mr. Williams.

Witness: Hello.

Crown: Mr. Williams, how often did you attend your daughter's soccer games and practices?

Witness: Um...I'd say about $70 \%$ of the time I was there.

Crown: Okay, and since you attended most of the games and practices, it's safe to assume that you were familiar with Brittany Shaw?

Witness: Brittany, yes of course.

Crown: Can you please explain to the court in what capacity did you, and the other parents, know Miss Shaw?

Witness: Brittany Shaw was a high school student who volunteered at the elementary school as the assistant soccer coach.

Crown: And how old would you say she was at the time?

Witness: I'm not sure, but if I had to guess, probably 16 or 17 .

Crown: Actually, she was only 15.

Crown: And do you recall an incident involving the defendant, Mr. Ferguson, and the then 15-year-old assistant soccer coach, Miss Shaw? Specifically, that Miss Shaw complained to the elementary school principal that Mr. Ferguson directed sexually explicit statements at her?

Defence: Objection! Hearsay.

Judge: Sustained. Witness, please do not answer the question. 
Crown: But considering that Mr. Ferguson was inappropriate with a 15 -year-old, is it so inconceivable that he would be inappropriate with a slightly younger girl? 10-year-old Susan Johnson?

Judge: That is enough! I will hold you for contempt of court if you address this issue any further!

Crown: No further questions, your Honour.

The witness is excused.

The Defence calls their second witness, the defendant, to the stand.

Defence: : Please state your name for the Court.

Witness: My name is John Ferguson.

Defence: Please state for the court the nature of you relationship with Susan Johnson

is/was?

Witness: She is my niece / was one of the girls I used to coach.

Defence: Mr. Ferguson, do you have a criminal record?

Witness: No, I do not.

Defence: Have you ever been accused of any sexual crimes?

Witness: No, I have not.

Defence: Just to be clear, there is no record, legally or otherwise, that you were sexually inappropriate with anybody?

Witness: No, there is no record whatsoever.

Defence: Tell me about the circumstances surrounding Miss Brittany Shaw, Mr.

Ferguson.

Witness: Well, as mentioned, she was a high school student who volunteered as the assistant soccer coach. She uh...developed a certain admiration for me, a "crush" if you will, and started wanting more attention. She wrote me letters expressing her feelings for me.

Defence: Did you ever confront her about this directly?

Witness: Yes, I did. And when I told her nothing could ever happen between us, she decided to get revenge by filing a false complaint that I was directing sexually inappropriate comments to her.

Crown: Objection! This reason for Miss Shaw's complaint is just speculation from the defendant.

Judge: Sustained.

Defence: Okay, so you never directed sexually explicit statements at Miss Shaw?

Witness: No, of course not.

Defence: And what happened to that complaint filed by Miss Shaw?

Witness: Nothing came of it. She did not pursue it and there is no official record of it.

Defence: And in terms of the present allegations, Mr. Ferguson, I am just going to be direct, did you, or did you not, sexually touch Susan Johnson once/12 times?

Witness: Absolutely not!

Defence: No further questions, your honour. 
The Crown cross examines the witness.

Crown: Hi Mr. Ferguson.

Witness: Hello.

Crown: You mentioned that you made an attempt to confront the assistant coach who had a "crush" on you?

Witness: Yes, I talked to her after practice one day.

Crown: Was there anyone around when you had this discussion with her?

Witness: No, we were alone.

Crown: Hmmm...so really, you could have made those sexually explicit comments to her while you were alone, couldn't you?

Defence: Objection! Leading the witness.

Judge: Sustained.

Crown: Okay, just let me clarify something, there was no one there to verify what you two talked about?

Witness: No, there was not.

Crown: Thank you Mr. Ferguson. Ok, let's move to the present issue at hand. Is it not true, that you drove Susan Johnson home and that you two were alone during this?

Witness: Yes, that's true.

Crown: In fact, aside from the 3 or 4 times that you had to drive Mr. Williams' daughter, you were completely alone with Susan Johnson in the car?

Witness: Yes, I was.

Crown: So again, Mr. Ferguson, you have no real proof of what took place during those car rides home?

Witness: No, I don't.

Crown: No further questions, your Honour.

The witness is excused.

The Judge provides the law and instructions for the jury.

Judge: Members of the jury, you have heard the testimony from the alleged victim, the defendant, and two other witnesses. It is now my responsibility to provide you with the law. Mr. Ferguson has been charged with the following:

151. SEXUAL INTERFERENCE- Every person who, for a sexual purpose, touches, directly or indirectly, with a part of the body or with an object, any part of the body of a person under the age of fourteen years

(a) is guilty of an indictable offence and liable to imprisonment for a term not exceeding ten years and to a minimum punishment of imprisonment for a term of forty-five days; or (b) is guilty of an offence punishable on summary conviction and liable to imprisonment for a term not exceeding eighteen months and to a minimum punishment of imprisonment for a term of fourteen days.

Please take into consideration all the information you have heard today, and do not let any biases you may have come into your decision making process. 


\section{Appendix C}

\section{Credibility Ratings Form}

Please answer the following questions.

Age:

Ethnicity:

Gender(Please circle): Male Female Primary Language:

Please answer each question by circling a number for each scale provided below.

1. How convincing was the testimony of the defendant, John Ferguson?

$\begin{array}{llllllc}1 & 2 & 3 & 4 & 5 & 6 & 7 \\ \text { Not at all } & & & & & & \begin{array}{c}\text { Extremely } \\ \text { Convincing }\end{array} \\ \text { Convincing } & & & & & & \end{array}$

2. How reliable was John Ferguson's memory?

$\begin{array}{ccccccccc}1 & 2 & 3 & 4 & 5 & 6 & 7 \\ \begin{array}{l}\text { Not at all } \\ \text { Reliable }\end{array} & & & & & & & \begin{array}{c}\text { Extremely } \\ \text { Reliable }\end{array}\end{array}$

3. In your opinion, how accurate was John Ferguson's memory?

$\begin{array}{cccccccc}1 & 2 & 3 & 4 & 5 & 6 & 7 \\ \begin{array}{c}\text { Not at all } \\ \text { Accurate }\end{array} & & & & & & & \begin{array}{c}\text { Extremely } \\ \text { Accurate }\end{array}\end{array}$

4. How convincing was the testimony of the complainant, Susan Johnson?

$\begin{array}{llllllll}1 & 2 & 3 & 4 & 5 & 6 & 7 \\ \begin{array}{l}\text { Not at all } \\ \text { Convincing }\end{array} & & & & & & & \begin{array}{c}\text { Extremely } \\ \text { Convincing }\end{array}\end{array}$

5. How reliable was Susan Johnson's memory?

$\begin{array}{cccccccc}1 & 2 & 3 & 4 & 5 & 6 & 7 \\ \begin{array}{l}\text { Not at all } \\ \text { Reliable }\end{array} & & & & & & & \begin{array}{c}\text { Extremely } \\ \text { Reliable }\end{array}\end{array}$

6. In your opinion, how accurate was Susan Johnson's memory?

$\begin{array}{cccccccc}1 & 2 & 3 & 4 & 5 & 6 & 7 \\ \begin{array}{c}\text { Not at all } \\ \text { Accurate }\end{array} & & & & & & & \begin{array}{c}\text { Extremely } \\ \text { Accurate }\end{array}\end{array}$




\section{Appendix D}

Verdict and Verdict Confidence Form

Please answer the following questions regarding your verdict.

With respect to the sexual interference charge, please rate the degree to which you find the defendant, Mr. John Ferguson, guilty.

Please circle one value on the scale below.

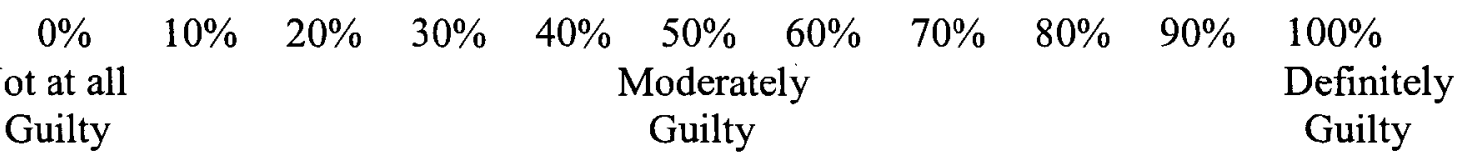

Please check one of the boxes below.

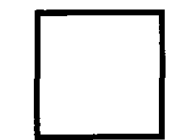

Not Guilty

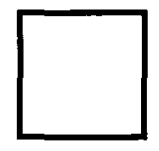

Guilty

How confident are you regarding your verdict decision (i.e., Guilty or Not Guilty)?

$\begin{array}{ccccccc}1 & 2 & 3 & 4 & 5 & 6 & \begin{array}{c}7 \\ \text { Extremely } \\ \text { Confident }\end{array} \\ \begin{array}{l}\text { Not Confident } \\ \text { at all }\end{array} & & & & & & \end{array}$

In your own words, please describe in the space below how you made your final verdict decision (i.e., what factors did you consider in reaching your verdict of guilty or not guilty?) 
Appendix E

Proposed Sentence Form

If you have found the defendant NOT GUILTY, please turn the page now to answer the next set of questions.

If you found the defendant GUILTY, please answer the questions below with regards to sentence recommendations for Sexual Interference.

In accordance with sections 151-153 of the Criminal Code of Canada which imposes a minimum sentence of $\mathbf{4 5}$ days imprisonment and a maximum sentence of $\mathbf{1 0}$ years imprisonment following the conviction of a person accused of committing sexual offences against children, how long would you recommend the defendant's prison term should be?

Please check one.

45 days
$2-11$ months
$1-2$ years
$3-4$ years
$5-6$ years
$7-8$ years
$9-10$ years


Appendix F

Beliefs Questionnaire

Please indicate how strongly you agree or disagree with each statement below.

1. Individuals who delay reporting child sexual abuse are more likely to be lying or to be making up their abusive experience.

$\begin{array}{ccccccc}1 & 2 & 3 & 4 & 5 & 6 & 7 \\ \text { Strongly } & & & & & \begin{array}{c}\text { Strongly } \\ \text { Agree }\end{array} \\ \text { Disagree } & & & & & & \end{array}$

2. Child sexual abuse by a family member is less likely to occur than child sexual abuse by a stranger.

$\begin{array}{ccccccc}1 & 2 & 3 & 4 & 5 & 6 & 7 \\ \text { Strongly } & & & & & \begin{array}{c}\text { Strongly } \\ \text { Agree }\end{array} \\ \text { Disagree } & & & & & & \end{array}$

3. Child sexual abuse is typically a one-time, isolated experience.

$\begin{array}{ccccccc}1 & 2 & 3 & 4 & 5 & 6 & 7 \\ \text { Strongly } & & & & & \text { Strongly } \\ \text { Disagree } & & & & & \text { Agree }\end{array}$

4. Adults who claim that they have been sexually abused as a child delay reporting the abuse because it did not cause any real emotional damage.

$\begin{array}{ccccccc}1 & 2 & 3 & 4 & 5 & 6 & 7 \\ \text { Strongly } & & & & & \begin{array}{c}\text { Strongly } \\ \text { Agree }\end{array} \\ \text { Disagree } & & & & & & \end{array}$

5. A family member who commits child sexual abuse should receive harsher punishment than a non-family member who commits child sexual abuse.

$\begin{array}{ccccccc}1 \quad 2 & 3 & 4 & 5 & 6 & 7 \\ \text { Strongly } & & & & & \begin{array}{c}\text { Strongly } \\ \text { Agree }\end{array} \\ \text { Disagree } & & & & & & \end{array}$


6. Children are less likely to be sexually abused by a trusted adult.

$\begin{array}{ccccccc}1 & 2 & 3 & 4 & 5 & 6 & 7 \\ \text { Strongly } & & & & & \begin{array}{c}\text { Strongly } \\ \text { Agree }\end{array} \\ \text { Disagree } & & & & & & \end{array}$

7. Non-violent child sexual abuse such as kissing, fondling, or touching are often reported right away.

$\begin{array}{cccccccc}1 \quad 2 & 3 & 4 & 5 & 6 & 7 \\ \text { Strongly } & & & & & \text { Strongly } \\ \text { Disagree } & & & & & \text { Agree }\end{array}$

8. Perpetrators who repeatedly abused a child should be given harsher punishment than those who abused a child only once.

$\begin{array}{ccccccc}1 & 2 & 3 & 4 & 5 & 6 & 7 \\ \text { Strongly } & & & & & \begin{array}{c}\text { Strongly } \\ \text { Agree }\end{array} \\ \text { Disagree } & & & & & & \end{array}$

9. Individuals who claim to have a one-time experience of child sexual abuse are more likely to have been simply confused by an innocent gesture.

$\begin{array}{ccccccc}1 \quad 2 & 3 & 4 & 5 & 6 & 7 \\ \text { Strongly } & & & & & \begin{array}{c}\text { Strongly } \\ \text { Disagree }\end{array}\end{array}$

10. Individuals who claim to have been sexually abused as a child are likely to be making up false claims to get back at the person $\mathrm{s} / \mathrm{he}$ is accusing.

$\begin{array}{ccccccc}1 \quad 2 & 3 & 4 & 5 & 6 & 7 \\ \text { Strongly } & & & & & \begin{array}{c}\text { Strongly } \\ \text { Agree }\end{array} \\ \text { Disagree } & & & & & & \end{array}$

11. Children who are sexually abused by a trusted adult often have difficulty accepting the abuse is wrong and therefore do not report it right away.

$\begin{array}{ccccccc}1 \quad 2 & 3 & 4 & 5 & 6 & 7 \\ \text { Strongly } & & & & & \begin{array}{c}\text { Strongly } \\ \text { Agree }\end{array} \\ \text { Disagree } & & & & & & \end{array}$


12. Adults who claim to have been sexually abused as a child cannot remember event details well enough to be reliable witnesses in a court of law.

$\begin{array}{ccccccc}1 & 2 & 3 & 4 & 5 & 6 & 7 \\ \text { Strongly } & & & & & \text { Strongly } \\ \text { Disagree } & & & & & \text { Agree }\end{array}$

13. Individuals can remember repeated childhood experiences very well but not experiences that happened only once.

$\begin{array}{lrlllll}1 & 2 & 3 & 4 & 5 & 6 & 7 \\ \text { Strongly } & & & & & \text { Strongly } \\ \text { Disagree } & & & & & \text { Agree }\end{array}$




\section{Appendix G}

\section{Manipulation Check Form}

Please answer the following questions. Circle the letter that corresponds to your answer.

1. How old is the complainant, Susan Johnson, at the time of the trial?
a. 12 years old
b. 25 years old
c. 30 years old
d. 40 years old

2. How old was the complainant, Susan Johnson, when the alleged sexual abuse took place?
a. 5 years old
b. 8 years old
c. 10 years old
d. 11 years old

3. What was the relationship of the defendant, John Ferguson, to the complainant, Susan Johnson, when the alleged abuse occurred?
a. Uncle
b. Father
c. Camp Counselor
d. Soccer Coach

4. How many times did the defendant, John Ferguson, allegedly abuse the complainant, Susan Johnson?
a. 1 time
b. 5 times
c. 12 times
d. 30 times

5. Where did the alleged incident of sexual abuse take place?
a. Home
b. Summer Camp
c. Car
d. Locker Room 
Appendix $\mathrm{H}$

\section{Written Debriefing Form}

\section{What are we trying to learn in this research?}

The present study aims to better understand how jurors make their decisions in criminal trials involving historic child sexual abuse. Historic child sexual abuse (HCSA) is defined as child sexual abuse that occurred in the distant past, and thus, involves delayed allegations, and consequently, delayed prosecution. In the present study, we were particularly interested in studying how three separate factors common in HCSA cases influence juror verdicts. These factors include (1) the length of delay (2, 15, or 30 years), (2) the complainant-defendant relationship (intrafamilial or extrafamilial), and (3) the number of assaults allegedly perpetrated by the defendant (one or 12 times).

\section{Why is this important to psychologists or the general public?}

The results from the present study will not only serve to improve our knowledge of the processes underlying juror decision-making in cases involving delayed allegations of child sexual abuse but also have important practical implications. First, given the traumatic nature of HCSA and the embarrassment and fear of disbelief that typically plague HCSA victims, the findings of the present study may help victims decide what, if any, legal avenues to pursue against the abuser. Further, since legal counsels may consider likely juror decisions in deciding whether or not to take a particular case, or whether to proceed with a trial or enter a guilty plea, it is important to understand how several factors, such as those that will be investigated in the present study, affect the adjudication of HCSA cases in Canadian courts.

We would like to ask that you please keep the nature of this study confidential from other potential participants as it may make our observations invalid. Your cooperation is greatly appreciated.

\section{What are our hypothesis or predictions?}

We predict that jurors will render higher ratings of guilt as well as assign higher credibility ratings to the complainant when there are shorter compared to longer delays in reporting the abuse. Further, we predict that a case of intrafamilial abuse (i.e., perpetrated by an uncle) will lead to higher ratings of guilt and longer sentence recommendations compared to a case of extrafamilial abuse (i.e., perpetrated by a former soccer coach). Lastly, we predicted that when the number of assaults is 12 rather than one, jurors will render higher ratings of guilt, assign higher credibility ratings to the complainant, and recommend longer sentence terms.

\section{Where can I learn more?}

The following journal article provides an excellent review of factors that affect the jury decision making process as it relates to real-life cases of historic child sexual abuse: 
Read, J. D., Connolly, D. A., \& Welsh, A. (2006). An archival analysis of actual cases of historic child sexual abuse: A comparison of jury and bench trials. Law and Human Behavior, 30, 259-285.

\section{What if I have questions later?}

If you have any questions regarding the study itself feel free to contact Charmagne Crescini (Principal Investigator, 520-2600 ext. 3695) or, Dr. Joanna Pozzulo (Faculty Advisor, 520-2600 ext. 1412). If you have any ethical concerns about this study please contact Dr. Janet Mantler (Chair of the Ethics Committee for Psychological Research at Carleton University, 520-2600 ext. 4173), or Dr. Mary Gick (Chair of the Department of Psychology at Carleton University, (520-2600 x2648).

Is there anything that I can do if I found this experiment to be emotionally troubling? We understand that the scenarios presented may be upsetting and/or anxiety provoking for some people. It is important that you contact the Health and Counselling Services at Carleton University (520-6674 or hcs@carleton.ca), your family doctor, or counselor if you have any concerns about the issues referred to in the present study.

Finally, we would like to thank you for your participation in the study. Your assistance will provide us with the resources we need to investigate how important factors affect the adjudication of cases involving delayed allegations of child sexual abuse. 
Appendix I

\section{Verbal Debriefing Form}

Thank you all for your time and for participating in my study. The aim of the present study is to better understand how jurors make their decisions in criminal trials involving historic child sexual abuse. HCSA is child sexual abuse that occurred in the distant past, typically, years or decades ago, and thus involves delayed allegations. The effects of three specific variables on juror decisions are investigated in this study: the first is the length of delay between the alleged abuse and the time of reporting (the transcript described either a 2-, 15-, or 30-year delay); the second is the relationship between the alleged victim and the defendant (either the defendant is described as the uncle or the former soccer coach of the alleged victim); and the last variable is the abuse frequency (either the abuse occurred once or 12 times). A secondary aim of the present study is to examine how your personal beliefs would affect your verdict decisions and as such, the 13-item beliefs questionnaire was also included.

Generally speaking, the present study aims to investigate how you, as potential jurors, would decide a historic child sexual abuse case based on the manipulations of these variables and how your pre-existing beliefs might affect your judgments.

Thank you again for your participation. Written debriefing forms are available for anyone interested or for anyone who wish to contact me for more information. 
Appendix $\mathbf{J}$

Reasons for Juror Verdicts

1. Not beyond a reasonable doubt / "Innocent until proven guilty"

2. Defendant should be brought to justice

3. Implausible situation (e.g., still bright out, difficult to perpetrate crime in cramped location)

4. Not enough evidence in general (Both testimonies equally weak/unreliable)

5. No other victims

6. No eyewitnesses

7. No physical evidence (e.g., DNA)

8. His word against her word (He-said, She-said case)

9. "Guilty until proven innocent" (i.e., Defendant did not show proof that he did not commit this act; no alibi)

10. Fear of future victims

11. Other victims are just too scared to come forward

12. Time delay/gap (complainant waited too long OR must be true since why would she come forward now?)

13. Frequency of the assault

14. Participants previous knowledge of sexual offences, similar cases/stories

15. Participants previous experience of CSA

16. Participants' biased feelings - e.g., stating, "being a woman" / "being pro-male"

17. Defense very convincing

18. Defense was not convincing

19. Defendant seems to be good citizen/good uncle

20. Defendant has no criminal record

21. Hearsay evidence regarding Brittany Shaw

22. Defendant's previous history of having sexual complaint against him (i.e., this can't be just a coincidence)

23. Defendant shows remorse

24. Defendant is an adult - capable of lying, manipulative, intimidating

25. Defendant was always alone with complainant or with others who filed a complaint against him (i.e., B. Shaw)

26. Defendant demeanor - not uncomfortable, overconfident, lack of emotional stress, not sympathetic

27. Defendants poor memory

28. Defendant went out of his way to give the alleged victim a ride home

29. Defendant's lack of prior formal sexual charges doesn't mean he can't commit one now

30. Defense's argument against B. Shaw accusations seems suspicious (e.g., absence of alleged letters she gave him?)

31. General testimony of complainant 
32. Crown was very convincing

33. Complainant testimony was not convincing (weak/shaky, not confident in her testimony; maybe mistaken)

34. Complainant seemed more trusting; had good character reference (good student)

35. Complainant maybe lying because she is mad, wants revenge or attention (has a motive)

36. Complainant has a history of lying

37. Complainant has vague/unreliable memory

38. Complainant demeanor would've changed after CSA

39. Complainant continued to get rides with defendant

40. Complainant demeanor - scared, emotional stress, hesitant (i.e., still traumatized)

41. Complainant lacks motive to lie

42. Complainant has a clear memory or that her memory was continuous and not recovered

43. Complainant was confident, convincing, consistent

44. Complainant was too young to realize it was wrong

45. Complainant was an easy/convenient target

46. Children do not lie

47. Children's memories are unreliable/easy to twist

48. Children cannot keep secrets so they would have disclosed earlier

49. Delayed disclosure is common for CSA victims

50. Memories can be easily altered/created

51. Sexual abuse is never forgotten 